Article

\title{
Analysis of Ferroresonance Phenomenon in 22 kV Distribution System with a Photovoltaic Source by PSCAD/EMTDC
}

\author{
Nattapan Thanomsat ${ }^{1}$ (D), Boonyang Plangklang ${ }^{1, *(1)}$ and Hideaki Ohgaki ${ }^{2}$ (D) \\ 1 Department of Electrical Engineering, Faculty of Engineering, Rajamangala University of Technology, \\ Thanyaburi, Pathumthani 12110, Thailand; nattapan@mail.rmutt.ac.th \\ 2 Institute of Advanced Energy, Kyoto University, Gokasho, Uji, Kyoto 6110011, Japan; \\ ohgaki.hideaki.2w@kyoto-u.ac.jp \\ * Correspondence: boonyang.p@en.rmutt.ac.th; Tel.: +66-86-899-2996
}

Received: 16 May 2018; Accepted: 29 June 2018; Published: 3 July 2018

\begin{abstract}
Overvoltage and overcurrent in the middle voltage (MV) $22 \mathrm{kV}$ and low voltage (LV) $0.4 \mathrm{kV}$ distribution network with photovoltaic (PV) rooftop system of the Provincial Electricity Authority of Thailand (PEA) have been investigated in order to show that these unwanted situations are caused by the ferroresonance phenomenon. This information would be useful to improve a better solution for the system protection when PV rooftops are integrated into the PEA distribution system. The software tool, PSCAD/EMTDC is used to study the overvoltage at the high side of open-delta and open-wye distribution transformer- and overcurrent at the low side of distribution transformer linked to the grid system via three single-phase fuse cutouts. The ferroresonance phenomenon can be observed when the PV rooftop system is linked to the low voltage side of the distribution transformer via three single-phase fuse cutouts. The results show a good similarity with the results from the simulation of the MV side and LV side of distribution transformers. Finally, the physical phenomena described to the overvoltage, overcurrent, and the destruction of the distribution transformer and other apparatus in load customers will occur when the system consists of the PV rooftop source, capacitance in long transmission line, nonlinear distribution transformer with saturation characteristic and the usage of single-phase switching cutouts in the system.
\end{abstract}

Keywords: ferroresonance; PV Rooftop system; PSCAD/EMTDC

\section{Introduction}

Ferroresonance is a special kind of resonance that occurs in the network with nonlinear elements, especially in transformers. When nonlinear inductance of the transformer core and the capacitance of the network are equal, ferroresonance happens. This equality can occur when the transformer is accidentally energized and de-energized in only one or two phases. Ferroresonance results in a high current and voltage across the inductance core and leads to the damage of the transformer as shown in Figure 1. There are a lot of articles in the literature which have discussed this phenomenon, for instance, References [1-8], and numerous simulation results of the possible ferroresonance happening in the high voltage side of the distribution network have been reported in References [9-12]. Gonen T. reported that ferroresonance is a transient phenomenon caused by the interaction of system capacitance with the nonlinear inductance of the transformer, energy source, and limited power losses [13]. However, Garikoitz B., et al. showed that the influence of ferroresonance is not only limited to the cable capacitance consideration, but also to several constructive, design, operation, and protective parameters [14]. There are a lot of ferroresonances in the configuration of distribution transformers. 
In 2003, Jacobson D.A.N. determined that seven different types of electrical systems are affected by ferroresonance phenomena [15].

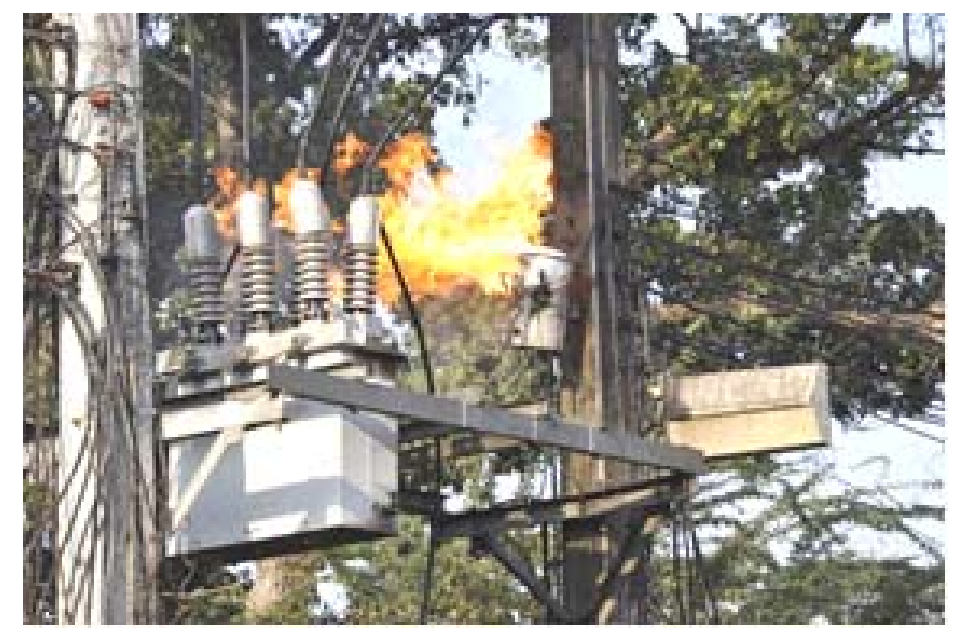

Figure 1. The transformer explosion caused in middle voltage (MV) [16].

This phenomenon has been considered and concentrated by the large-scale electricity generators that produce and distribute energy to the end user. Nowadays, electricity is not only produced by large-scale producers but also by the small-scale end users. The development of the electricity generation technology and energy policies together with the environmental crisis have persuaded the end users to produce electricity from renewable energy by themselves. Therefore, ferroresonance caused by energizing and de-energizing transformers which are connected to these small-scale electricity producers must be of concern.

One of the small-scale electricity generation systems from renewable energy is the photovoltaic (PV) system, which directly converts solar energy into electricity. It is one of the significant and clean sources of renewable energy. In the year 2012, Thailand has successfully installed nearly $2300 \mathrm{MW}$ of solar energy, 99 percent of which is in the form of commercially centralized installations (solar farms), while the housing-sized solar PV (solar rooftop) shares a very small percentage [17,18]. However, according to the explosive growth of urbanization in Thailand, which increases every year (approximately 1.6 percent per year [17]), the usage of rooftop solar energy dramatically increased. In contrast with this growth, the information about the end users that can produce electricity is not fully known by the provincial electricity authority of Thailand (PEA), which is the main electricity distributor in Thailand. Therefore, ferroresonance phenomena from accidentally energizing and de-energizing the distribution transformer should be awarded and concentrated. The study in Reference [19] confirmed that ferroresonance does exist in the power transformer, which is connected to the PV system. However, the complete distribution network is not considered. Moreover, the analysis of the ferroresonance effect on the load is still not considered. With more information on ferroresonance in distribution systems with PV systems connected to it, the PEA will be aware of the effect of this phenomenon on the transformers and the power qualities [20-29].

Based on these facts, the simulation-based study of the ferroresonance effects in the distribution network with PV system sources will be presented in this paper. The major contribution of this work is the analysis of the type of ferroresonance that occurs in systems together with its effect on the system. The frequency analysis technique known as the Fast Furrier Transformation (FFT) will be used to distinguish the type of ferroresonance in the frequency domain. After the introduction in the first part, the organization of this paper is arranged in 4 parts. In the second part, the preliminary and Theory of ferroresonance will be presented. System modeling and the simulation results will be mentioned, analyzed and discussed in the third and fourth part, respectively. Finally, the conclusion will be addressed in the last part. 


\section{Preliminary and Theory}

\subsection{Ferroresonance in the Transformer}

There are basically four different ferroresonance modes that can happen in a power system, that is, the fundamental mode, the subharmonic mode, the quasi-periodic mode and the chaotic mode, as shown in Figure 2.

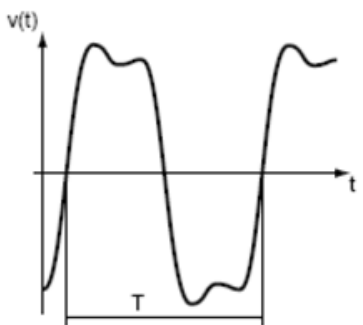

(a) Fundamental mode

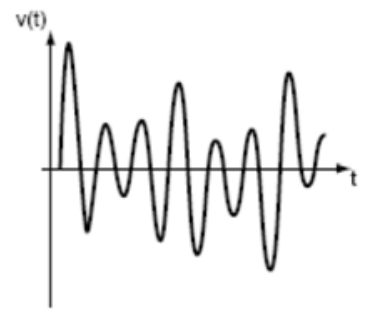

(c) Quasi-periodic mode

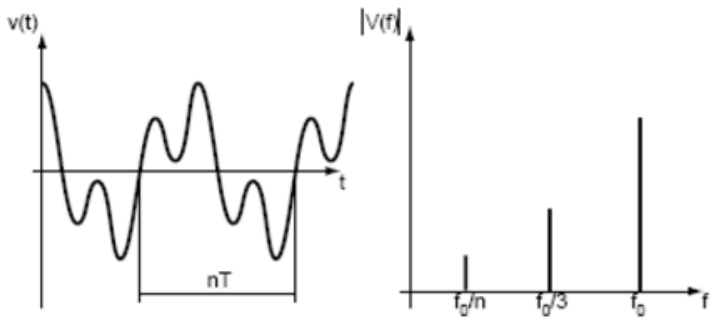

(b) Subharmonic mode

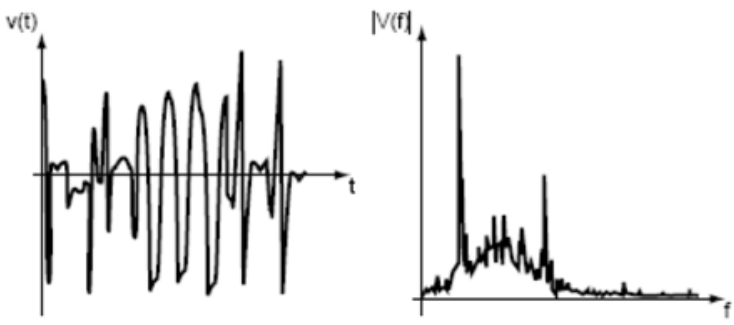

(d) Chaotic mode

Figure 2. The ferroresonance modes and their frequency responses [30].

- Fundamental mode

The signal has the same period as the power system $(T)$. The frequency spectrums consist of the fundamental frequency component followed by the decreasing magnitude of the $n$-th odd harmonic.

- Subharmonic

The signal has a period which is a multiple of the source period $(n T)$. The frequency spectrums consist of the fundamental frequency component followed by the decreasing contents of the n-th subharmonic.

- Quasi-periodic

The signal is not periodic but has the repetitive pattern. The frequency spectrums are discontinuous and defined as $n f_{1}+m f_{2}$, where $n$ and $m$ are integers.

- Chaotic

The signal is not periodic and the frequency spectrums are continuous.

In order to achieve the analytical solution of ferroresonance, the simplified equivalent circuit of the transformer, which consists of a nonlinear inductance, equivalent capacitance, equivalent resistance, and energy source, is considered as shown in Figure 3. 


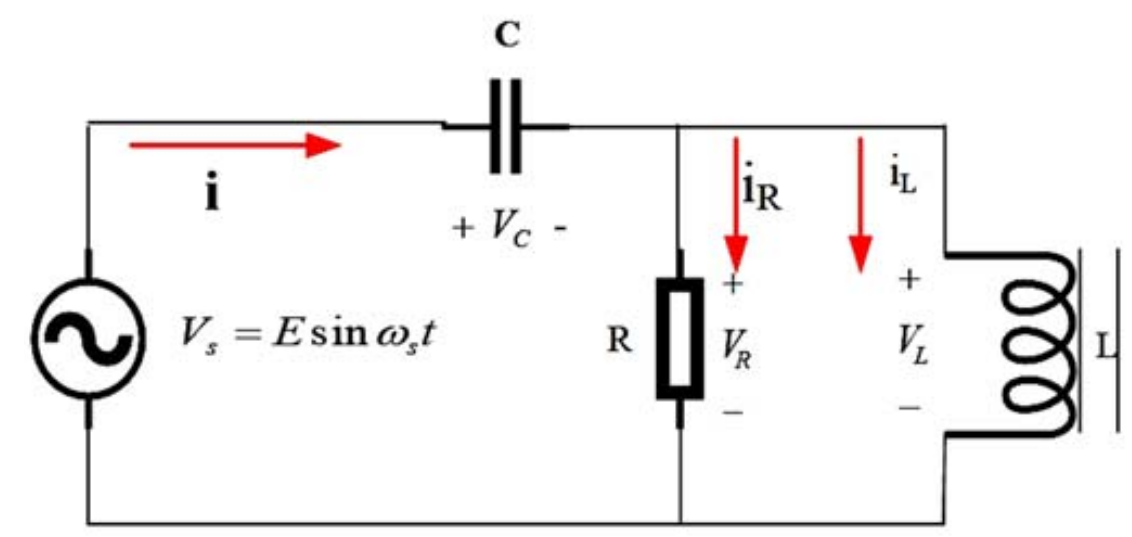

Figure 3. The equivalent circuit of the transformer for ferroresonance analysis.

Suppose that the magnetization curve of the nonlinear inductance is represented in Figure 4, therefore, this curve can be approximated by the $n$ th-order polynomial

$$
i_{L}=a \phi+b \phi^{n}
$$

where $i_{L}$ is a magnetizing current, $\phi$ is a magnetic flux in the transformer core, $a$ is a coefficient of the linear term that corresponds to unsaturated magnetizing inductance and $b$ is a coefficient of the nonlinear term.

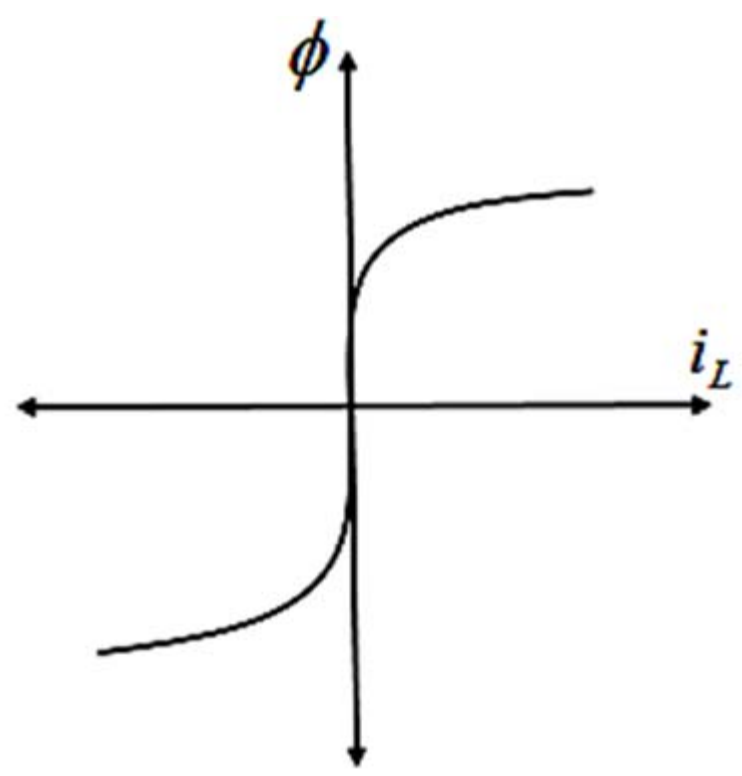

Figure 4. The magnetization curve of transformer inductance.

The analytical solution of ferroresonance in Figure 3 can be achieved by the harmonic balance method. The differential equation for the flux linkage with the magnetization curve approximated by Equation (1) is presented by

$$
\frac{d^{2} \phi}{d t^{2}}+\frac{1}{R C} \frac{d \phi}{d t}+\frac{1}{C}\left(a \phi+b \phi^{n}\right)=\omega_{s} E \cos \omega_{s} t
$$


In order to achieve the steady-state flux $\phi$ by the harmonic balance method, a simplified version of Equation (2) can be written in the form of Duffin's equation [31,32]

$$
\frac{d^{2} \phi}{d t^{2}}+\frac{1}{R C} \frac{d \phi}{d t}+\omega_{0}^{2} \phi+\omega_{2}^{2} \phi^{n}=\omega_{s} E \cos \omega_{s} t
$$

where $\omega_{0}=\sqrt{\frac{a}{c}}$ and $\omega_{2}=\sqrt{\frac{b}{C}}$.

For the fundamental mode $(n=1,3,5, \ldots)$, the steady-state solution of Equation (2) is written in the form

$$
\phi=\Phi \sin \left(\omega_{s} t+\theta\right)=\Phi_{x} \sin \omega_{s} t+\Phi_{y} \cos \omega_{s} t
$$

where $\Phi=\sqrt{\Phi_{x}^{2}+\Phi_{y}^{2}}$ and $\theta=\tan ^{-1}\left(\frac{\Phi_{y}}{\Phi_{x}}\right)$.

We substitute Equation (4) into Equation (2) and apply the approximation of term $\sin ^{n}\left(\omega_{s} t+\theta\right)$ with

$$
\sin ^{n}\left(\omega_{s} t+\theta\right) \cong k_{1} \sin \left(\omega_{s} t+\theta\right)
$$

where $k_{1}=\frac{(-1)^{n-1}}{2^{n-2}}\left(\begin{array}{c}n \\ \frac{n-1}{2}\end{array}\right)$.

Then when we equate the $\sin \omega_{s} t$ term and neglect $\cos \omega_{s} t$ with the higher order terms, the following equations are obtained:

$$
\begin{gathered}
{\left[-\left(\omega_{s}^{2}-\omega_{0}^{2}\right)+k_{1} \omega_{2}^{2} \Phi^{n-1}\right] \Phi_{x}-\left(\frac{\omega_{s}}{R C}\right) \Phi_{y}=0} \\
{\left[-\left(\omega_{s}^{2}-\omega_{0}^{2}\right)+k_{1} \omega_{2}^{2} \Phi^{n-1}\right] \Phi_{y}+\left(\frac{\omega_{s}}{R C}\right) \Phi_{x}=\omega_{s} E}
\end{gathered}
$$

When Equations (6) and (7) are solved for the coefficients $\Phi_{x}, \Phi_{y}$, the solution of Equation (4) can be obtained. Finally, the solution for the other modes of ferroresonance can be achieved with similar procedures.

Ferroresonance can be explained by using a graphical approach. Consider the V-I characteristics of inductance and capacitance, as shown in Figure 5.

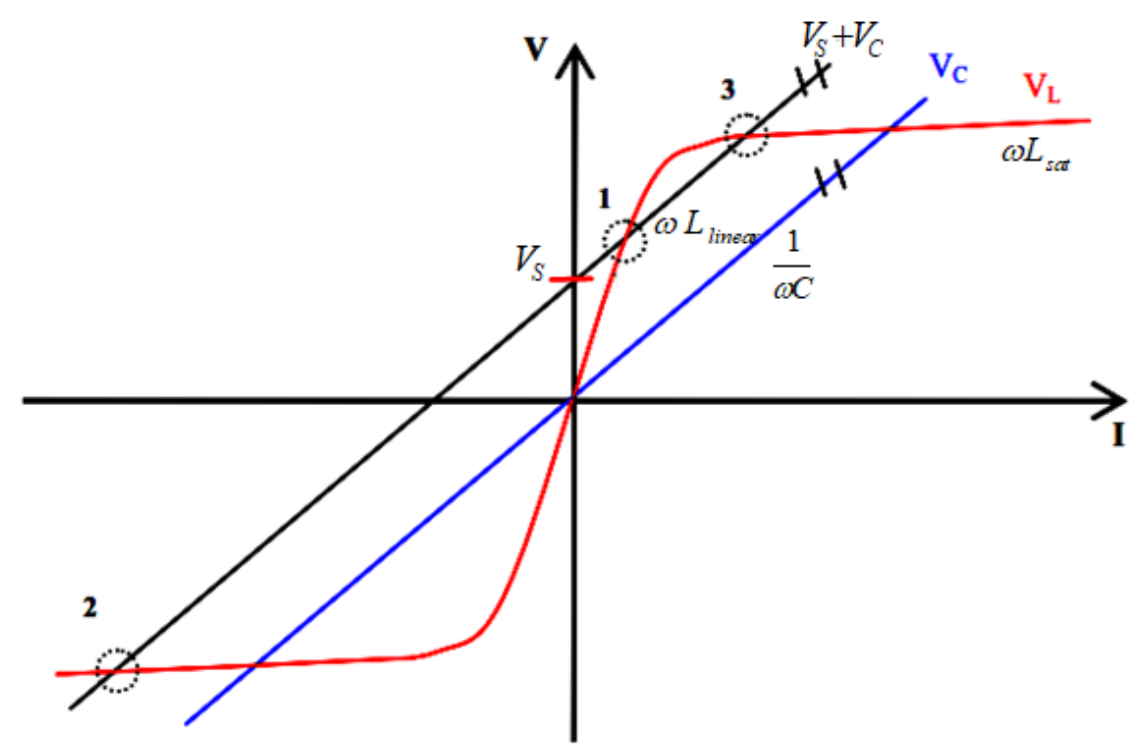

Figure 5. The graphical solution of a series ferroresonance circuit [33]. 
Since the inductive reactance of the transformer core consists of two regions, linear and nonlinear characteristics, the possible operation points are obtained as the intersection of $V_{L}$ and $V_{S}+V_{C}$ are as follows:

- Point 1 is a stable non-ferroresonance mode. At this point, the circuit is working with the inductive mode and remains there in the steady-state.

- Point 2 is a stable ferroresonance mode. At this point, the circuit is working with the inductive mode with both high voltage and current. This solution also remains there in the steady-state.

- Point 3 is an unstable mode and the solution will not remain there in the steady-state.

\subsection{The Distribution Transformer under the Emerged or De-Energized Modes}

The delta and wye transformer connection with energy sources is modeled in the form of an inductor and capacitor network as shown in Figure $6 \mathrm{a}, \mathrm{b}$, respectively. These capacitors exist in the underground cables or the overhead power lines with respect to earth. Whereas the inductors represent the magnetizing inductance of the transformers.
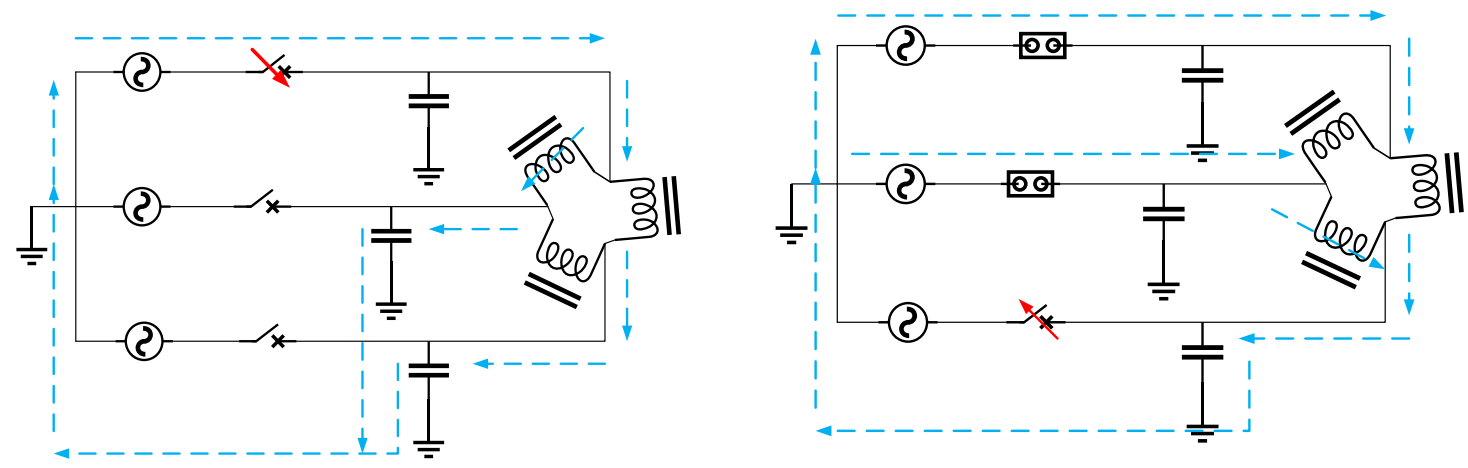

(a) The line supplying a transformer with delta connected
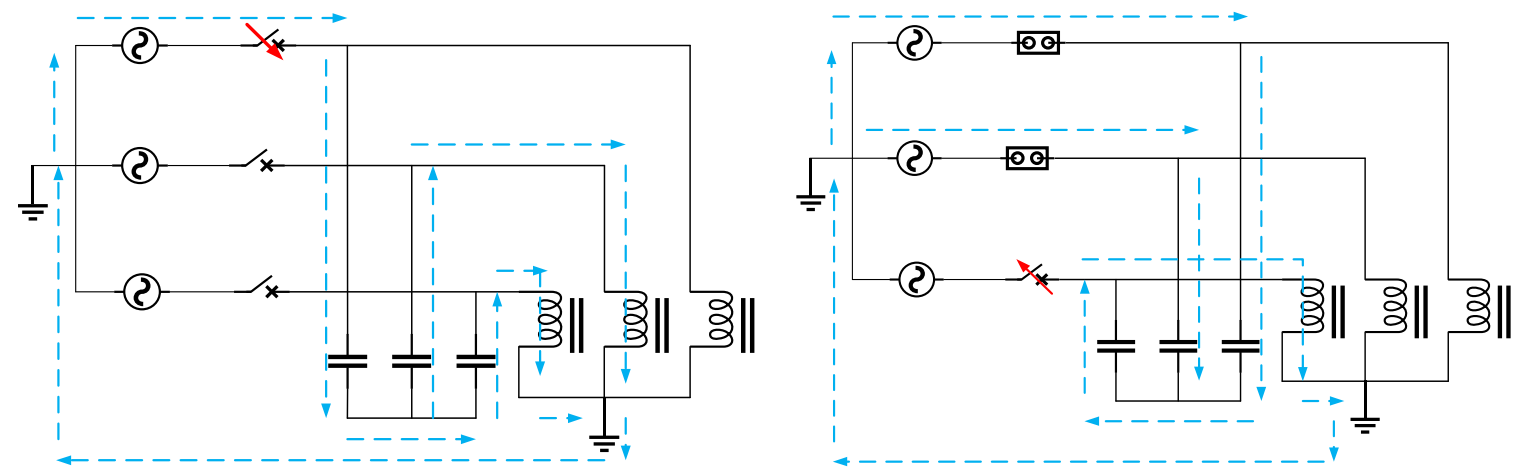

(b) The line supplying a transformer with wye-ground connected

Figure 6. The transformer connection scheme.

From the connection scheme in Figure 6, the series circuit of the capacitor, inductor and supply source is used for analyzing the ferroresonance in each phase, as shown in Figure 7. 

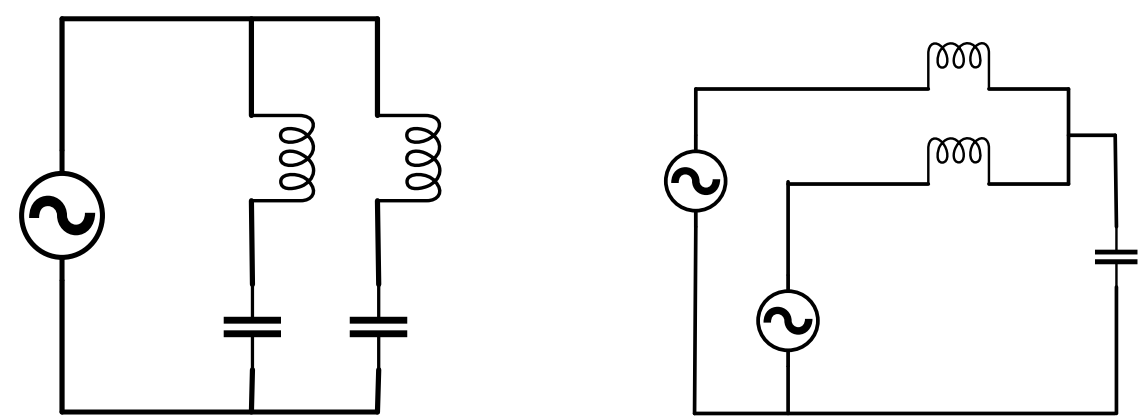

(a) The ferroresonance circuits for each phase of the circuit in Figure 6a
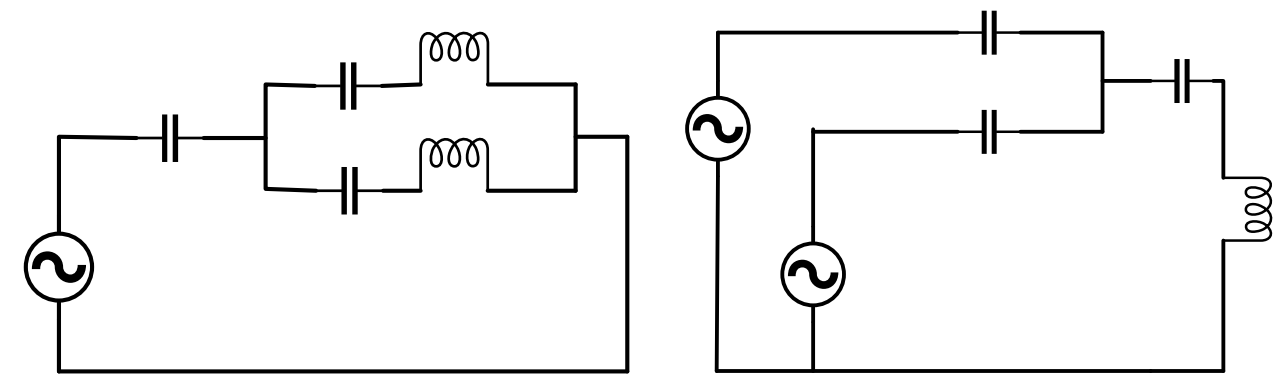

(b) The ferroresonance circuits for each phase of the circuit in Figure $6 \mathrm{~b}$

Figure 7. The ferroresonance circuits for each phase of the circuits in Figure 6.

\section{System Modeling for Simulation}

In this section, the modeling of the distribution system with a PV connected system is arranged. Since an experiment with ferroresonance is a destructive experiment, the demonstration is simulated using the PSCAD/EMTDC software. In this study, three different cases are considered.

\subsection{The System Under Considering}

The system consists of a local load of the PEA network. Through the $22 \mathrm{kV}$ distribution system, the local load has 3 transformers (one unit of 1 MVA and two units of $500 \mathrm{kVA}$ ) for condos, suburban homes and townhouses, and suburban homes with total installed PV rooftops, respectively. The total $500 \mathrm{~kW}$ installation capacity of the PV rooftop system consists of a PV array with Maximum Power Point Tracking (MPPT) and the simplified inverter without the anti-islanding system. The produced energy is incorporated into the $22 \mathrm{kV}$ grid through the step-up transformer. The distribution line to the system consists of two underground cables of 20-km length and a PI transmission line section of 200-m length. Moreover, there are three cutout switches at every connection line, as shown in Figure 8.

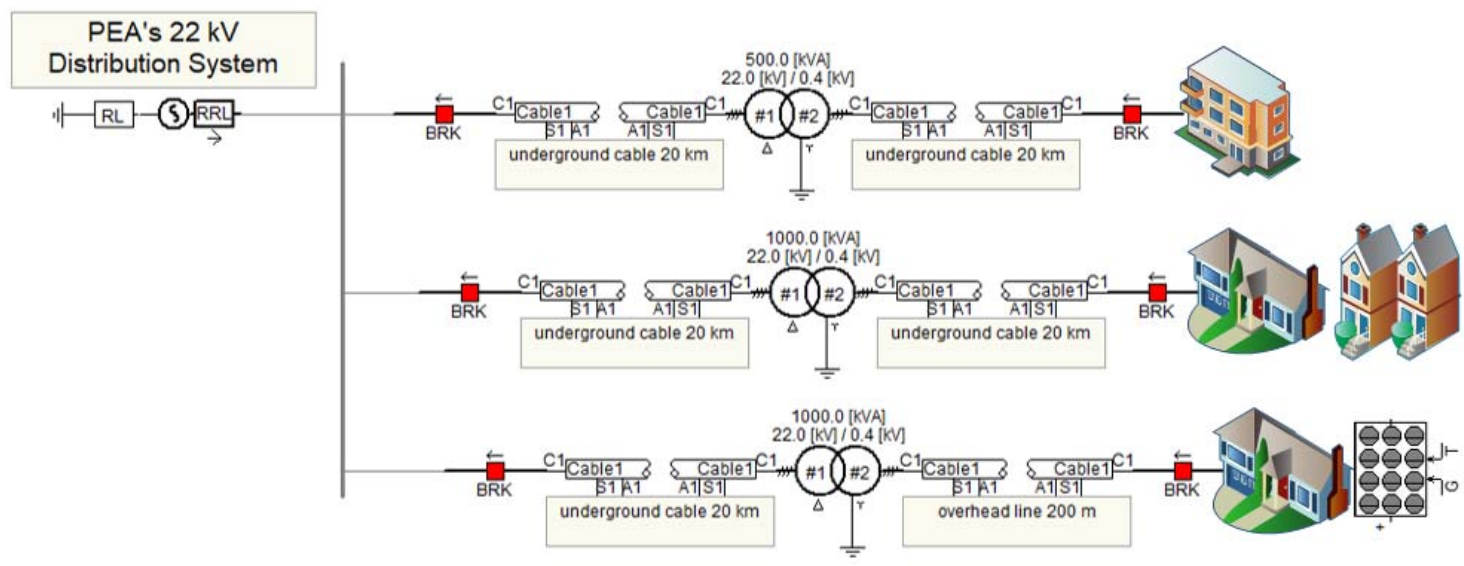

Figure 8. The simulation system model. 
3.2. Simulation Case I: The Effect of Ferroresonance on the High Voltage (HV) Side of the Distribution Transformer

The purpose of Case I is to consider the effect that ferroresonance causes due to the connection of a 1 MVA and $500 \mathrm{kVA}$ transformers to a PV system. The single line diagram of this case is shown in Figure 9 and its corresponding series inductance and capacitance (LC) ferroresonance circuit is modeled in Figure 10. Moreover, the required parameters and data are summarized in Table 1.

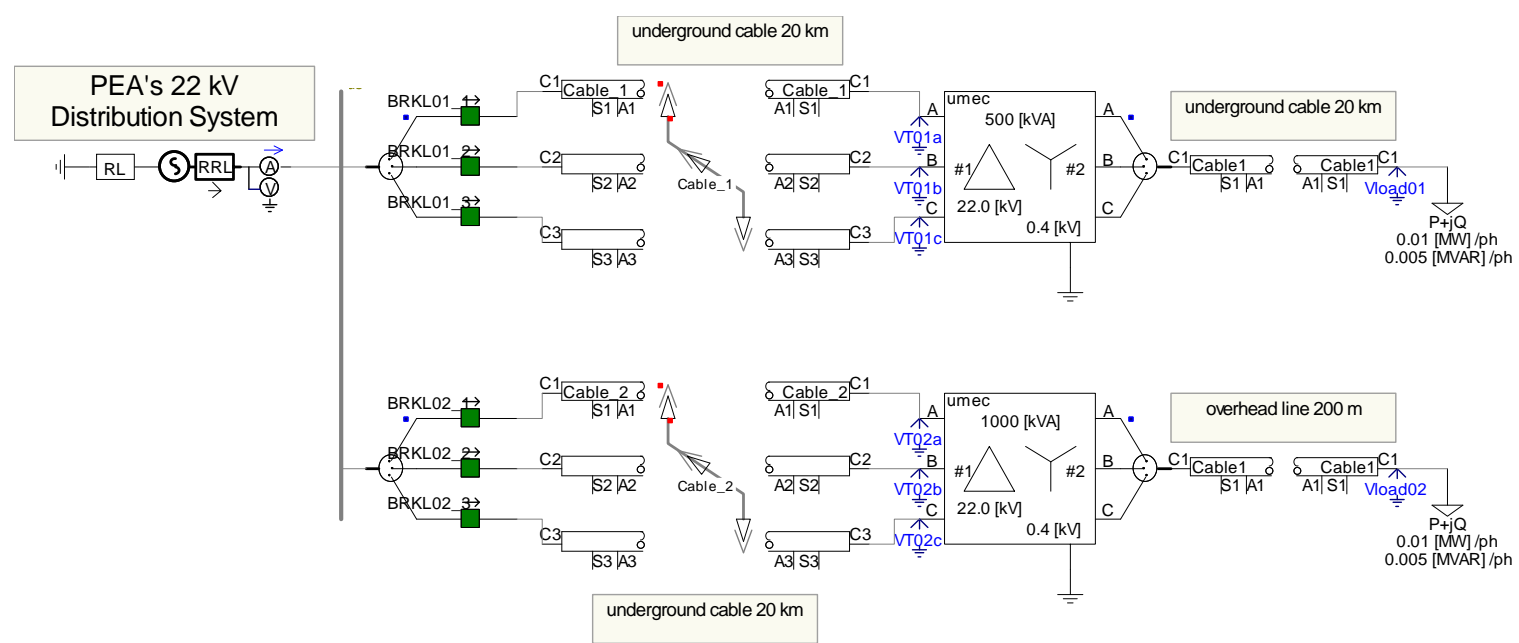

Figure 9. The single line diagram of the 1 MVA and $500 \mathrm{kVA}$ transformer connections.

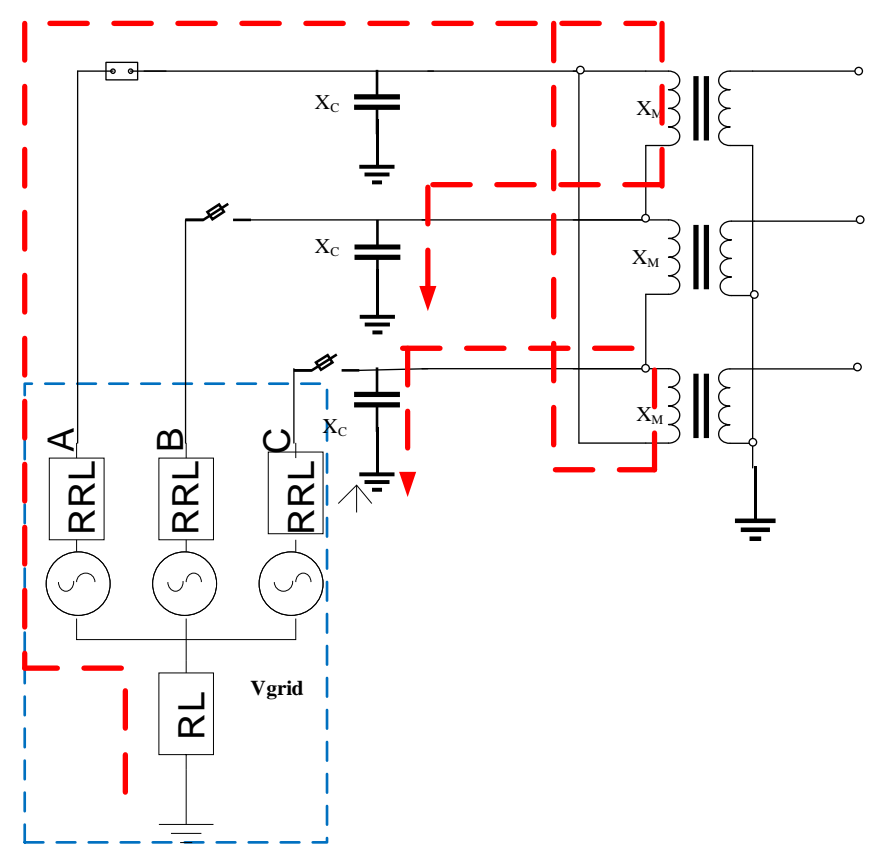

Figure 10. The series LC ferroresonance circuit for Case I. 
Table 1. The parameters for simulation Case I.

\begin{tabular}{|c|c|c|}
\hline Name & Parameter & Value \\
\hline \multirow{3}{*}{ Vgrid } & Base MVA (3 phase) & $10 \mathrm{MVA}$ \\
\hline & Base voltage (L-L, RMS) & $32 \mathrm{kV}$ \\
\hline & Base frequency & $50 \mathrm{~Hz}$ \\
\hline \multirow[b]{2}{*}{ Cable 1} & Steady-state frequency & $50 \mathrm{~Hz}$ \\
\hline & Segment length & $20 \mathrm{~km}$ \\
\hline \multirow{2}{*}{ Cable 2} & Steady-state frequency & $50 \mathrm{~Hz}$ \\
\hline & Segment length & $20 \mathrm{~km}$ \\
\hline \multirow{5}{*}{$\mathrm{T} 1$} & Transformer MVA & $500 \mathrm{kVA}$ \\
\hline & Primary voltage & $22 \mathrm{kV}$ \\
\hline & Secondary voltage & $0.4 \mathrm{kV}$ \\
\hline & Type: Delta-Wye ground & \\
\hline & Base operation frequency & $50 \mathrm{~Hz}$ \\
\hline \multirow{5}{*}{$\mathrm{T} 2$} & Transformer MVA & $1 \mathrm{MVA}$ \\
\hline & Primary voltage & $22 \mathrm{kV}$ \\
\hline & Secondary voltage & $0.4 \mathrm{kV}$ \\
\hline & Type: Delta-Wye ground & \\
\hline & Base operation frequency & $50 \mathrm{~Hz}$ \\
\hline Load 1 & Customer Load 1 & $0.01 \mathrm{MW}+0.005 \mathrm{MVAR}$ per phase \\
\hline Load 2 & Customer Load 2 & $0.01 \mathrm{MW}+0.005$ MVAR per phase \\
\hline
\end{tabular}

Three single-phase circuit breakers (BRK) are connected with underground cables (BRKL01_1, BRKL01_2, BRKL01_3, BRKL02_1, BRKL02_2, and BRKL02_3). The measuring equipment is represented by VT01a, VT01b, VT01c, VT02a, VT02b, and VT02c. Single-phase circuit breakers are consequently switched from phase $\mathrm{C}, \mathrm{A}$ and $\mathrm{B}$ for de-energization. After that, they are switched from phase $\mathrm{B}, \mathrm{A}$ and $\mathrm{C}$ for energization.

3.3. Simulation Case II and Case III: The Impact of the PV Rooftop System on the Distribution Transformer and Suburban Homes

The purpose of Case II is to consider the effect of ferroresonance that is caused by the cuts in the PV system at the interconnection transformers $500 \mathrm{kVA} \mathrm{LV}$ and suburban home sides. The purpose of Case III is to consider the effect of ferroresonance that is caused by the cuts in the PV system at the interconnection transformer $500 \mathrm{kVA}$ LV side with the increasing installation capacity of the PV system step by step and to observe the effects of the change. The single line diagram for expressing these two cases is shown in Figure 11 and its corresponding series LC ferroresonance circuit is modeled in Figure 12. Additionally, the required parameters and data are summarized in Table 2.

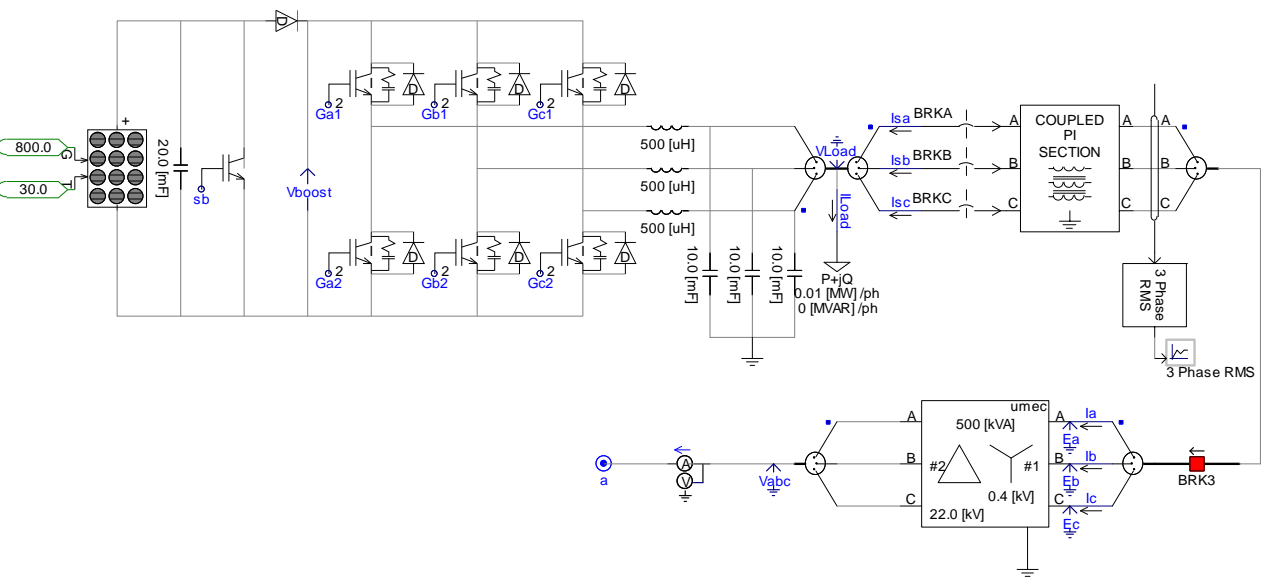

Figure 11. The single line diagram of a PV rooftop system with a $500 \mathrm{kVA}$ transformer and a light load connected. 


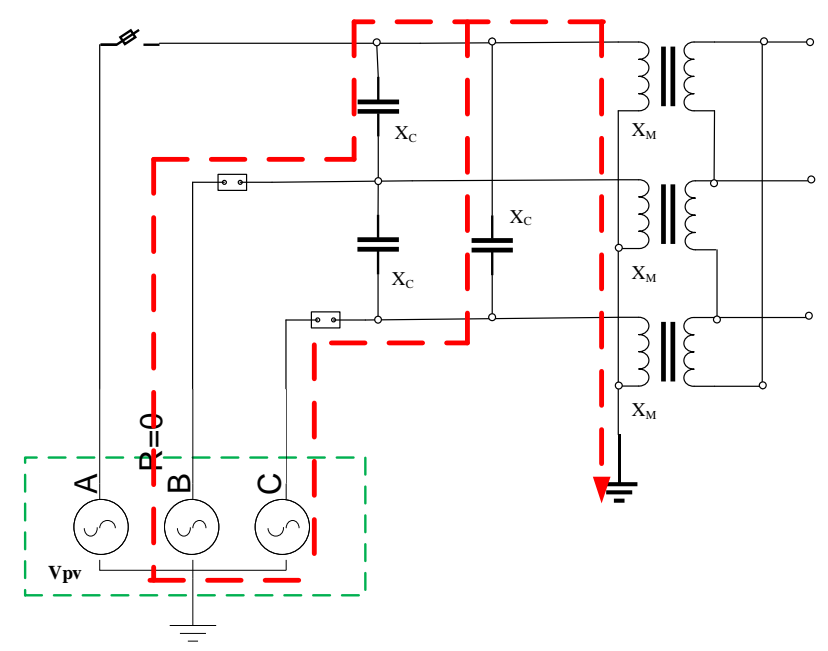

Figure 12. The series LC ferroresonance circuit for Cases II and III.

Table 2. The parameters for simulation Cases II and III.

\begin{tabular}{ccc}
\hline Name & Parameter & Value \\
\hline & Ref. irradiance & $1000 \mathrm{~W} / \mathrm{m}^{2}$ \\
& Ref. Temperature & $25{ }^{\circ} \mathrm{C}$ \\
& Effective area per cell & $0.01 \mathrm{~m}^{2}$ \\
PV module data & Series resistance per cell & $0.02 \Omega$ \\
& Shunt resistance per cell & $1000 \Omega$ \\
& Diode ideality factor & 1.5 \\
& Band gap energy & $1.103 \mathrm{eV}$ \\
& Saturation current at reference conditions per cell & $1 \times 10^{-12} \mathrm{kA}$ \\
& Short circuit current at the ref. conditions per cell & $0.0025 \mathrm{kA}$ \\
& Temperature Coefficient of photocurrent & $0.001 \mathrm{~A} / \mathrm{K}$ \\
\hline \multirow{2}{*}{ Coupled PI Section } & Line Rated Frequency & $50 \mathrm{~Hz}$ \\
& Line Length & $0.2 \mathrm{~km}$ \\
\hline \multirow{2}{*}{ T3 } & Transformer MVA & $500 \mathrm{kVA}$ \\
& Primary voltage & $0.4 \mathrm{kV}$ \\
& Secondary voltage & $22 \mathrm{kV}$ \\
& Type: Wye ground-Delta & \\
& Base operation frequency & $50 \mathrm{~Hz}$ \\
\hline Load 3 & Customer Load 3 & $0.01 \mathrm{MW} \mathrm{per} \mathrm{phase}$ \\
\hline
\end{tabular}

Three single-phase circuit breakers are connected with the transmission line PI section (BRKA, $\mathrm{BRKB}$, and BRKC). The measuring equipment is represented by $\mathrm{Ea}, \mathrm{Eb}, \mathrm{Ec}, \mathrm{Ia}, \mathrm{Ib}$, Ic, VLoad and ILoad. Single-phase circuit breakers are consequently switched from phase B, C and A for de-energization. After that, they are switched from phase A, C and B for energization.

\section{Simulation Results and Discussion}

The simulation results from the model in Section 3 are considered, analyzed and discussed in this section.

\subsection{Case I: The Ferroresonance Effect on the $500 \mathrm{kVA}$ and 1 MVA Transformer with Condos, Suburban and} Town House Loads

For Case I, the single-phase de-energization and energization at BRKL01 and BRKL02 illustrate the ferroresonance overvoltage of the 1 MVA and $500 \mathrm{kVA}$ transformers. The simulation results also show that the overvoltage occurs between $0.25-0.7 \mathrm{~s}$ as seen in Figures 13 and 14, respectively. 


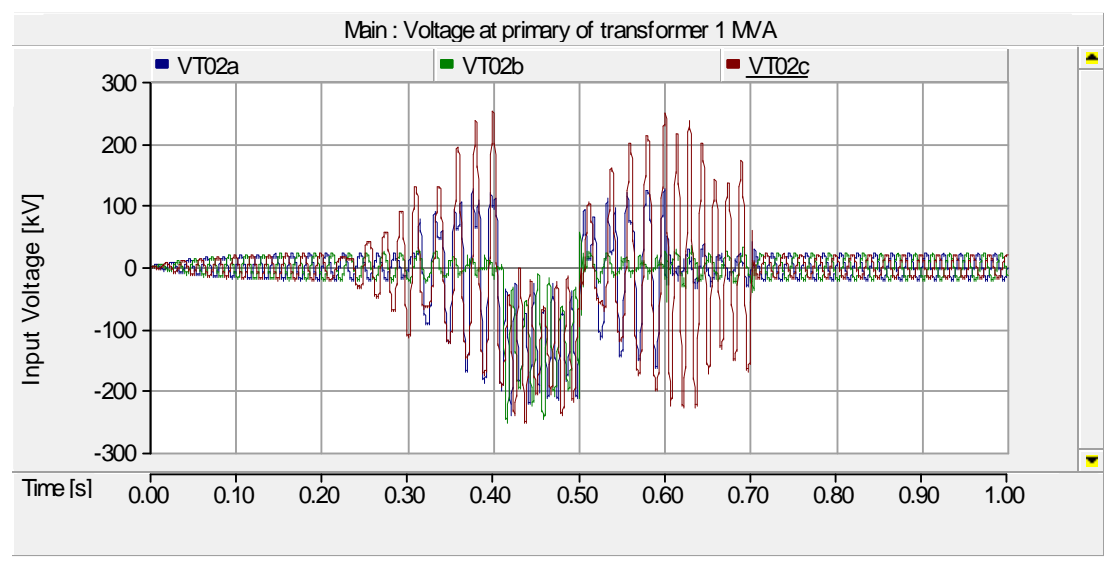

Figure 13. The ferroresonance overvoltage at the HV side transformer 1 MVA.

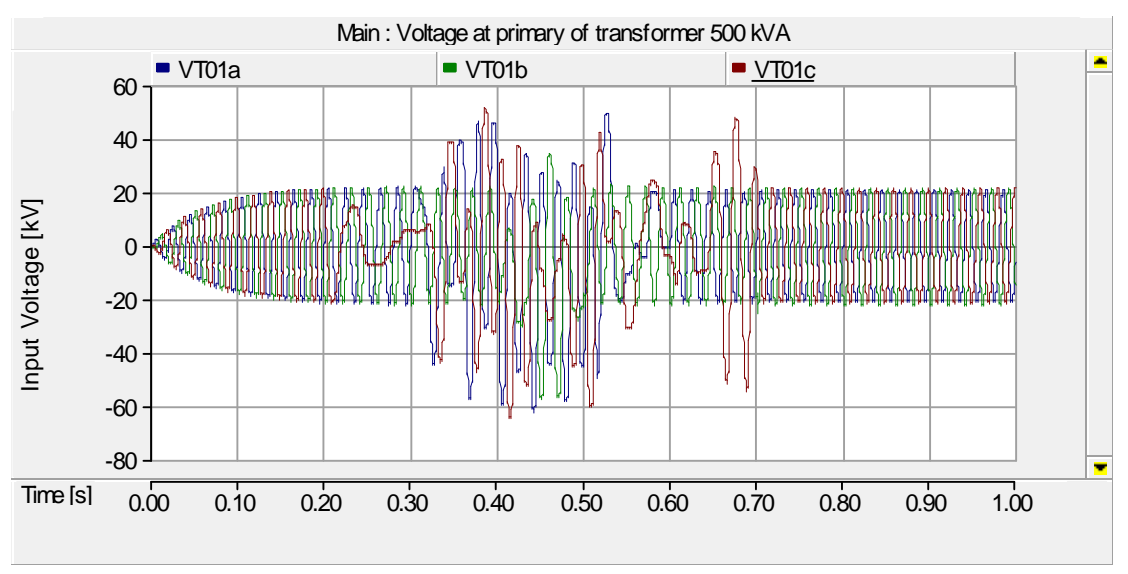

Figure 14. The ferroresonance overvoltage at the HV side transformer $500 \mathrm{kVA}$.

However, ferroresonance does not occur when the distribution transformer is not in the saturation region and the three-phase circuit breaker is connected and disconnected at the same time. These characteristics are shown in Figures 15 and 16, respectively.

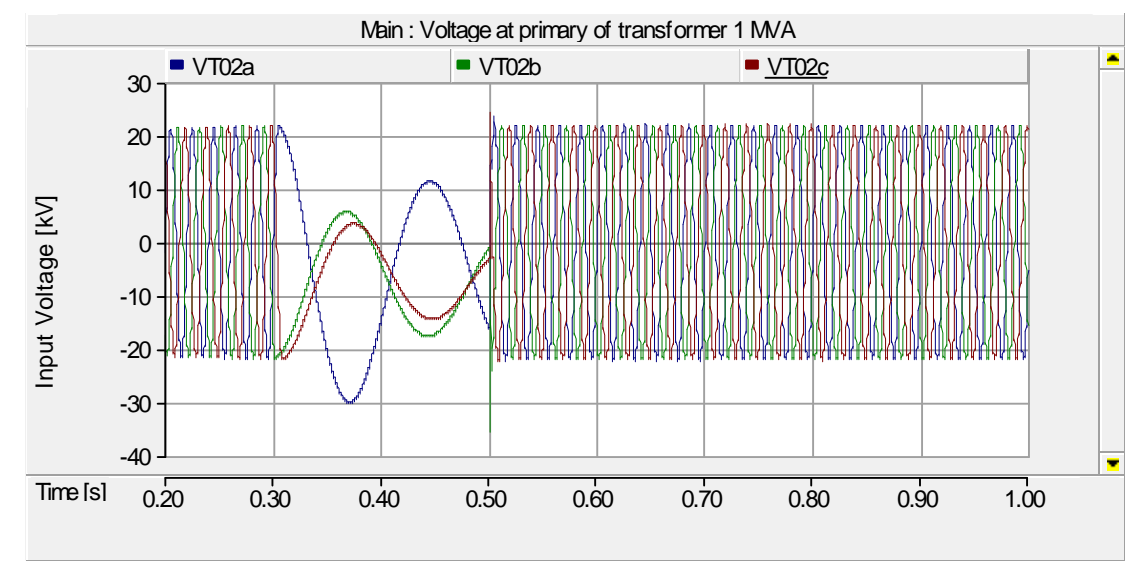

Figure 15. The three-phase circuit breaker disconnecting and connecting without the saturation transformer 1 MVA at the HV side. 


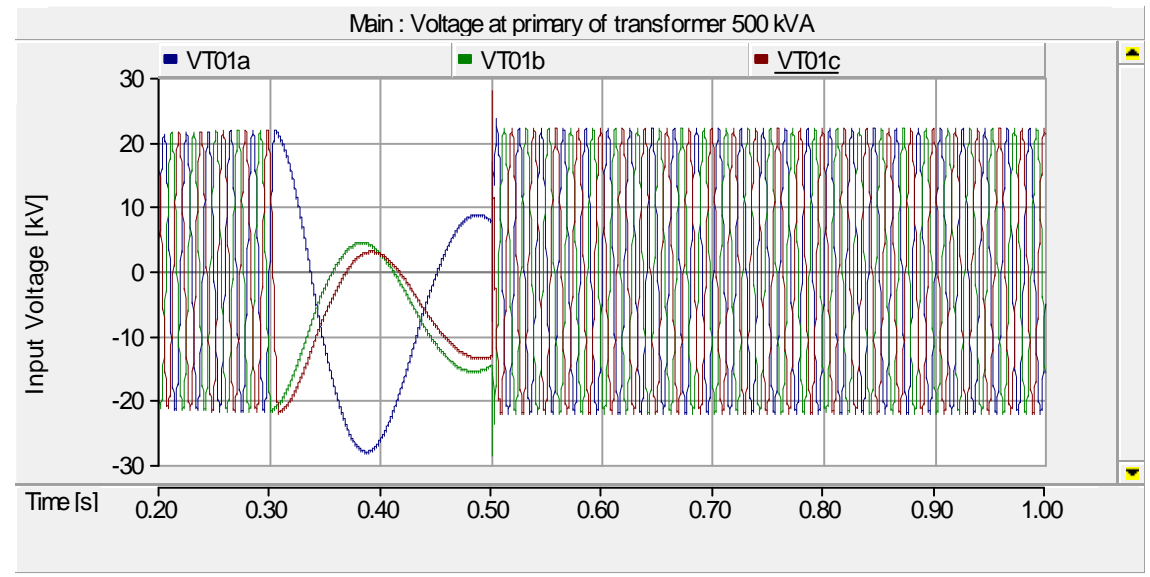

Figure 16. The three-phase circuit breaker disconnecting and connecting without the saturation transformer $500 \mathrm{kVA}$ at the HV side.

4.2. Case II: The Ferroresonance Effect on the 500 kVA Transformer LV Side with Suburban Home Load and the Total 500 kW Installation Capacity of PV Rooftop Systems

In Case II, the de-energization and energization in the phase by phase scheme are illustrated. First, the BRKB opens at $0.3 \mathrm{~s}$. The corresponding phase voltage and current are shown in Figure 17.
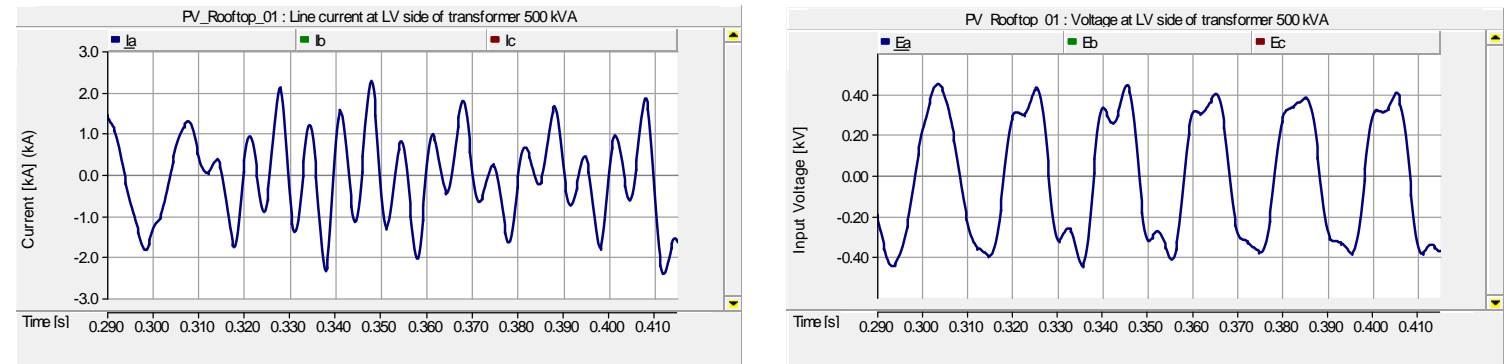

(a) Phase A
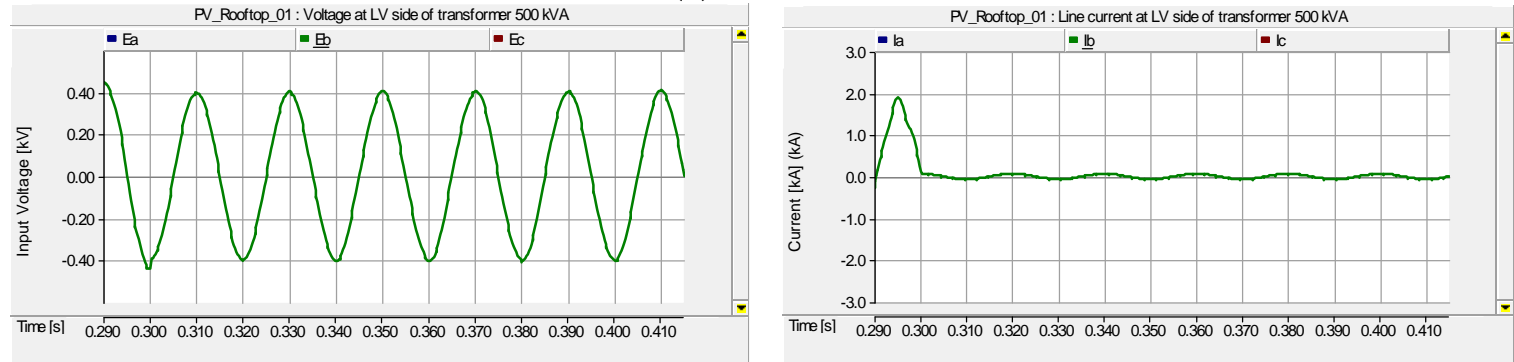

(b) Phase B
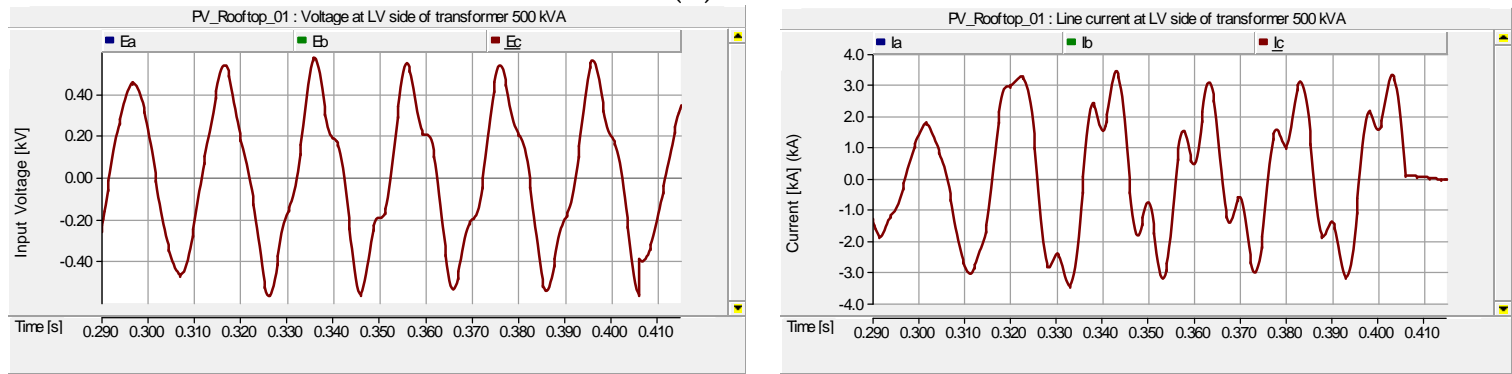

(c) Phase C

Figure 17. The voltage and current at the LV side $(0.4 \mathrm{kV})$ transformer $500 \mathrm{kVA}$ when the BRKB open circuit is at $0.3 \mathrm{~s}$. 
The frequency analysis results is shown in Figure 17. The corresponding frequency spectrums are obtained as shown in Figure 18.
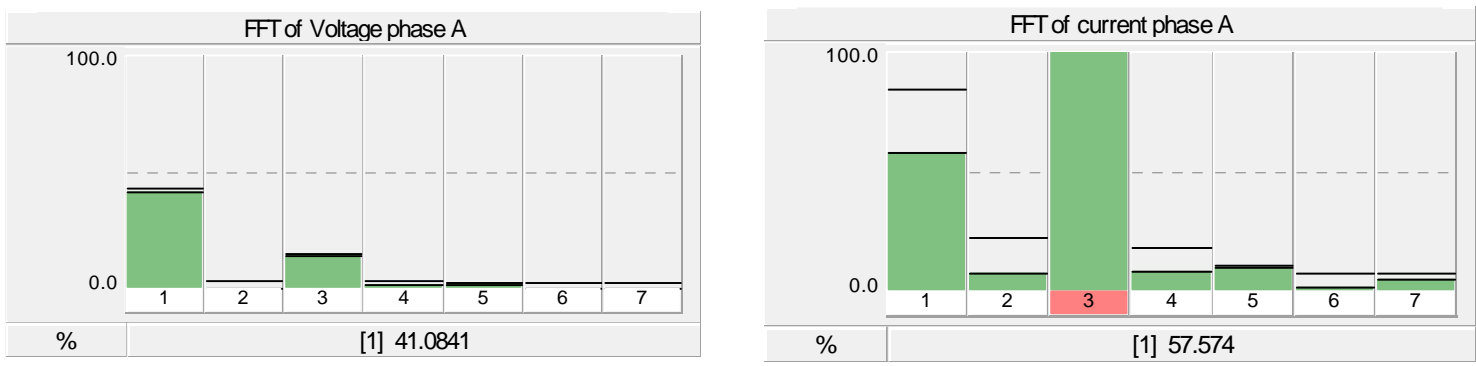

(a) Phase A
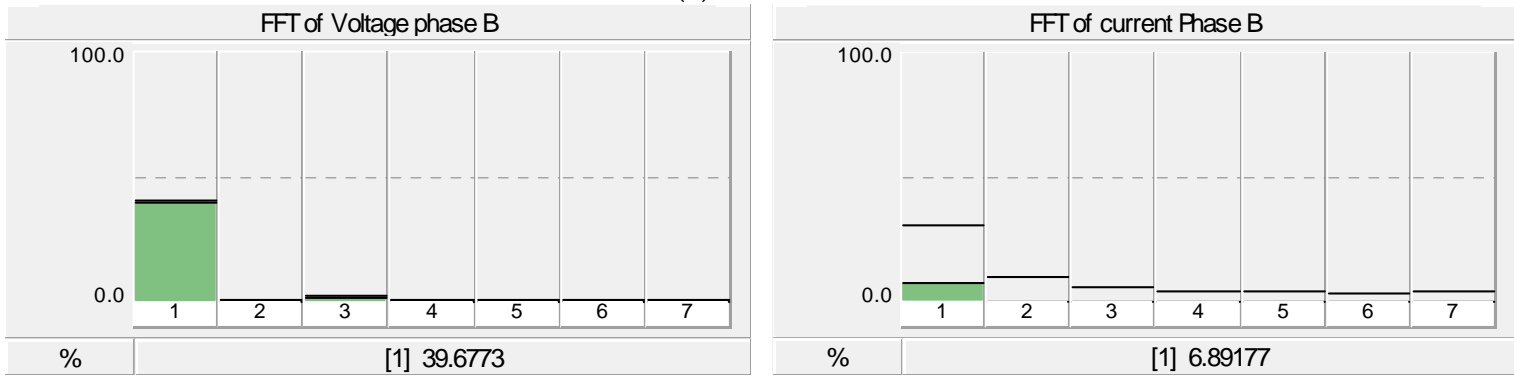

(b) Phase B
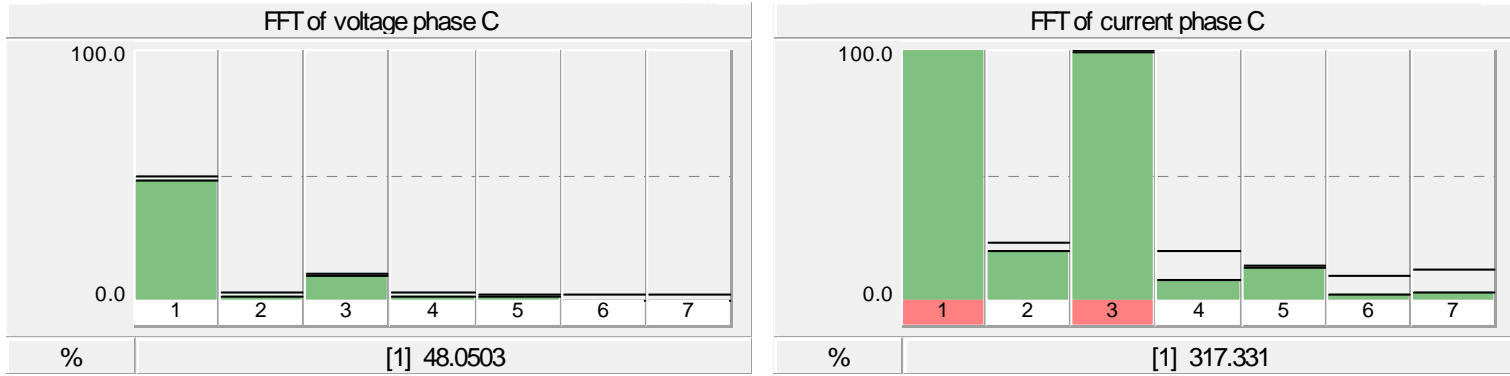

(c) Phase C

Figure 18. The frequency spectrums of the phase voltage and current at the LV side $(0.4 \mathrm{kV})$ transformer $500 \mathrm{kVA}$ when the BRKB open circuit is at $0.3 \mathrm{~s}$.

From the results in Figures 17 and 18, it is clearly seen that phase A and C are affected by the ferroresonance. Their voltage consists of the fundamental mode ferroresonance while the current consists of the combination of fundamental mode and quasi-periodic mode ferroresonances.

Secondly, a phase $\mathrm{C}$ is consequently disconnected by opening BRKC at time $0.4 \mathrm{~s}$. The corresponding phase voltage and current are shown in Figure 19.
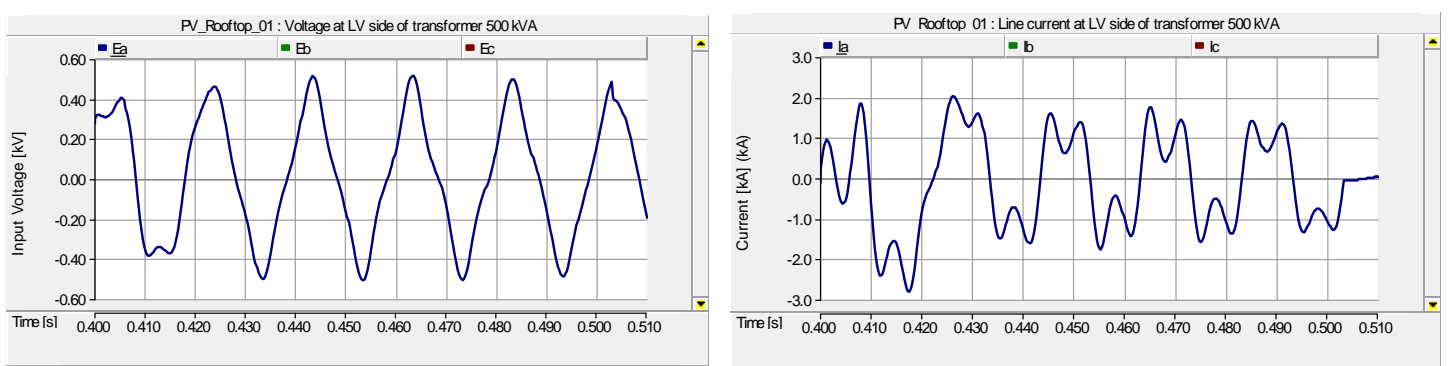

(a) Phase A

Figure 19. Cont. 

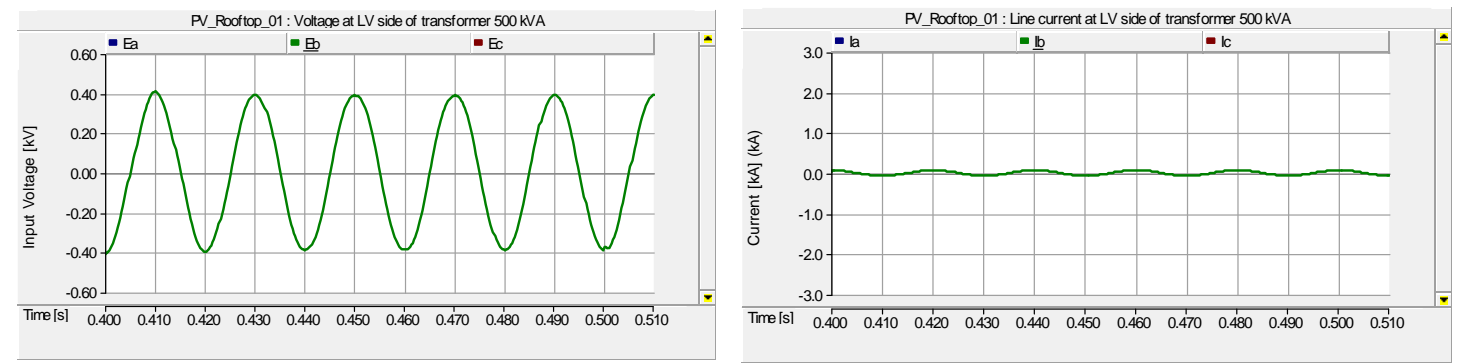

(b) Phase B
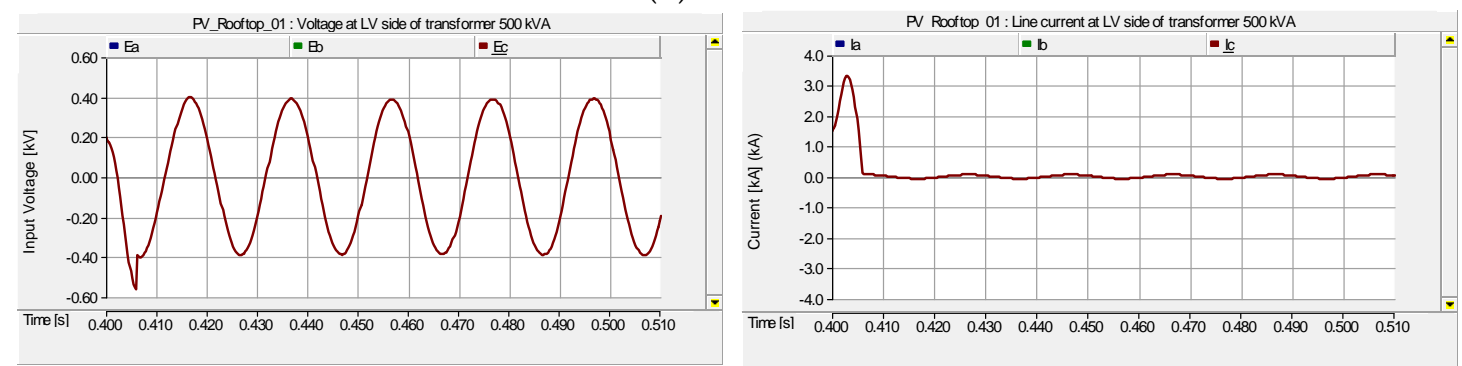

(c) Phase C

Figure 19. The voltage and current at the LV side $(0.4 \mathrm{kV})$ transformer $500 \mathrm{kVA}$ when the BRKC open circuit is at $0.4 \mathrm{~s}$.

The frequency analysis of the results is shown in Figure 19. The corresponding frequency spectrums are obtained as shown in Figure 20.
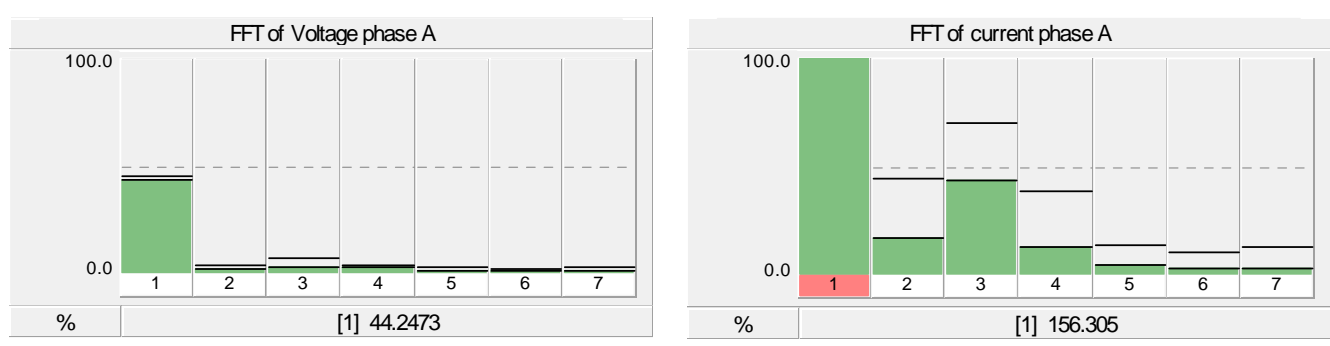

(a) Phase A
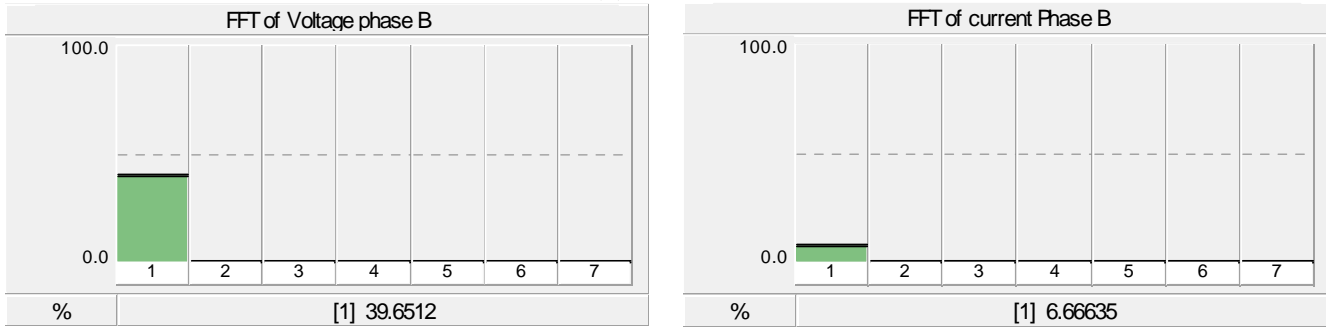

(b) Phase B
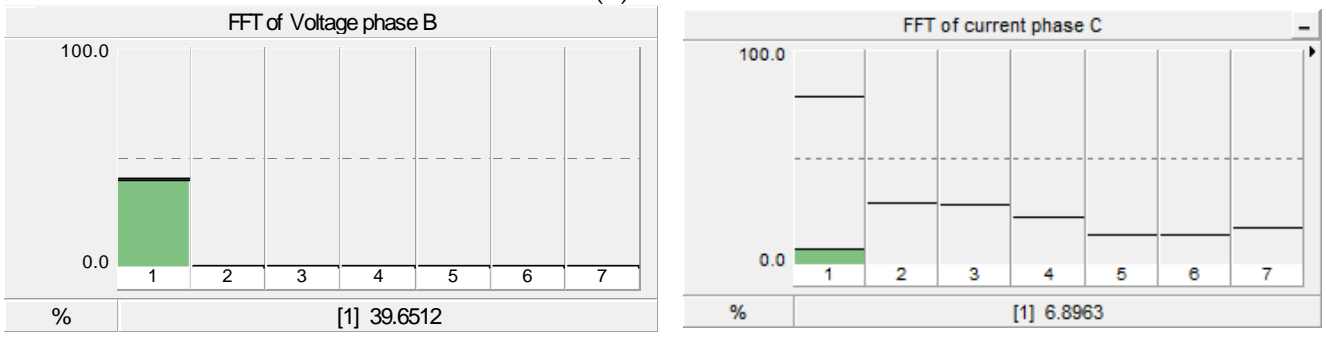

(c) Phase C

Figure 20. The frequency spectrums of the phase voltage and current at the LV side $(0.4 \mathrm{kV})$ transformer $500 \mathrm{kVA}$ when the BRKC open circuit is at $0.4 \mathrm{~s}$. 
From the results in Figures 19 and 20, it can be clearly seen that only phase A is affected by ferroresonance. Its voltage consists of fundamental mode ferroresonance while the current consists of the combination of fundamental mode and quasi-periodic mode ferroresonances.

Finally, phase A is disconnected by opening BRKA at time $0.5 \mathrm{~s}$. The corresponding phase voltage and current are shown in Figure 21.
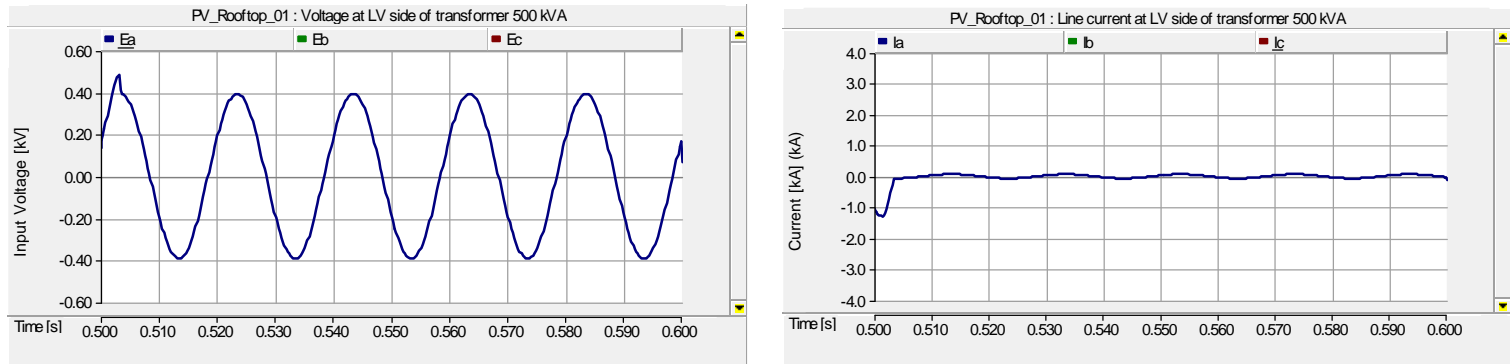

(a) Phase A
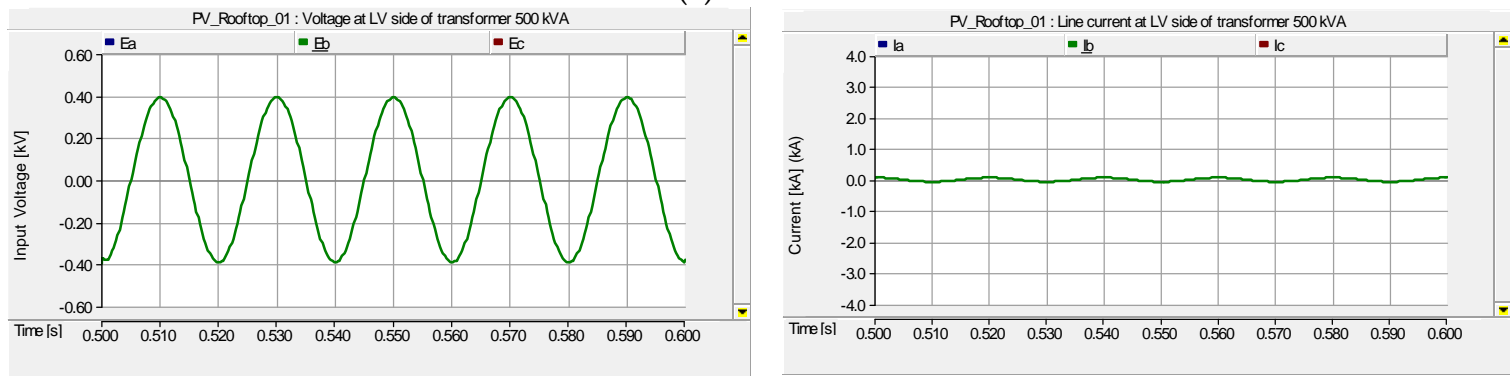

(b) Phase B
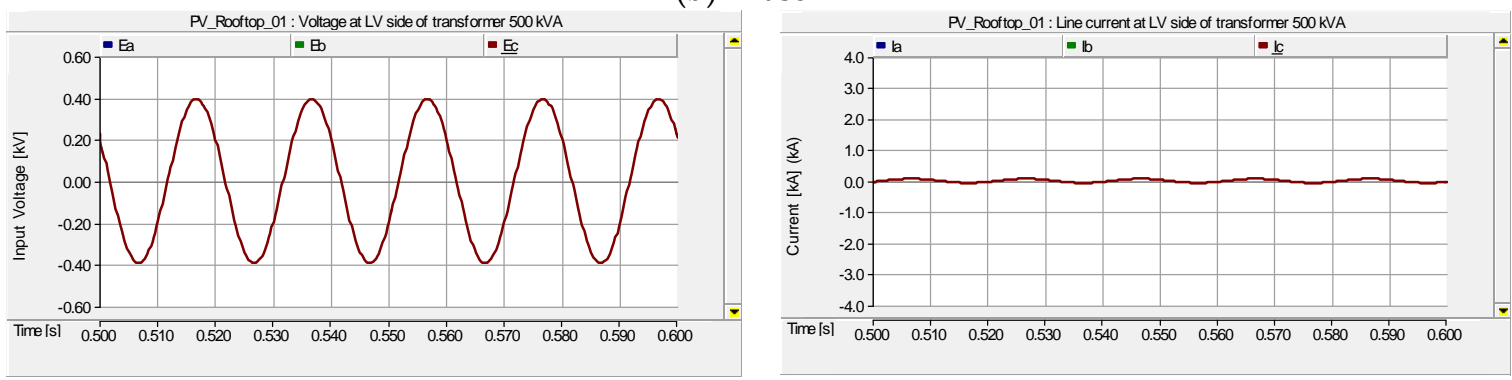

(c) Phase C

Figure 21. The voltage and current at the LV side $(0.4 \mathrm{kV})$ transformer $500 \mathrm{kVA}$ when the BRKA open circuit is at $0.5 \mathrm{~s}$.

The corresponding frequency spectrums of Figure 21 are obtained and shown in Figure 22.
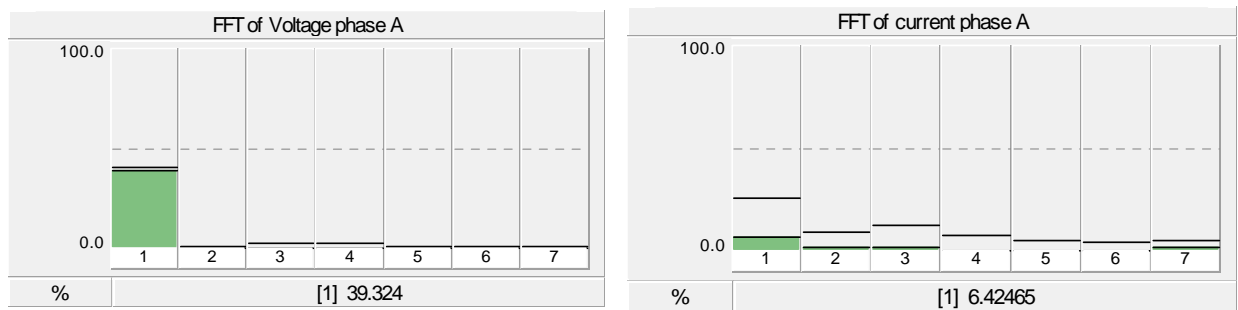

(a) Phase A

Figure 22. Cont. 

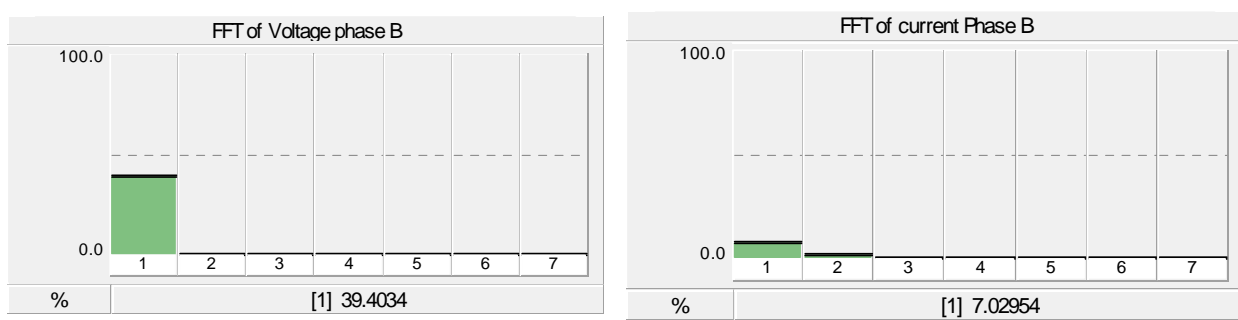

(b) Phase B
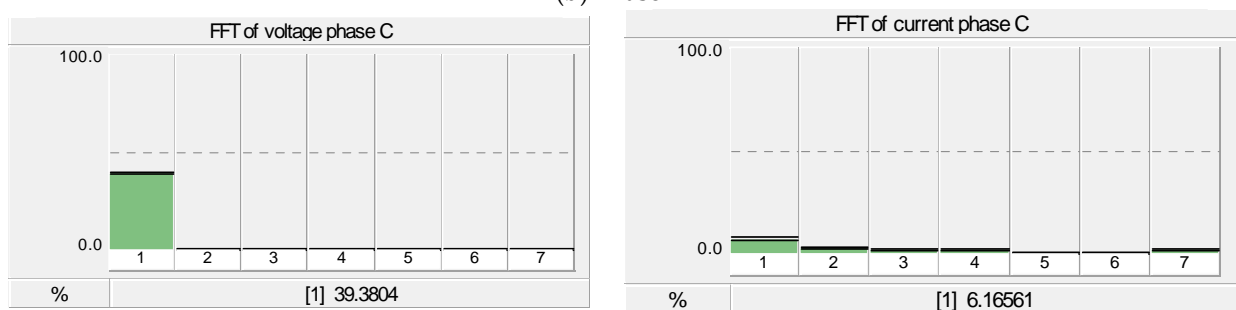

(c) Phase C

Figure 22. The frequency spectrums of the phase voltage and current at the LV side $(0.4 \mathrm{kV})$ transformer $500 \mathrm{kVA}$ when the BRKA open circuit is at $0.5 \mathrm{~s}$.

From the results in Figures 21 and 22, the voltage and current of all phases are not affected by ferroresonance.

After all the circuit breakers are disconnected, the connection characteristics of each phase are considered. First, the BRKA is closed at $0.6 \mathrm{~s}$. The corresponding phase voltage and current are shown in Figure 23.
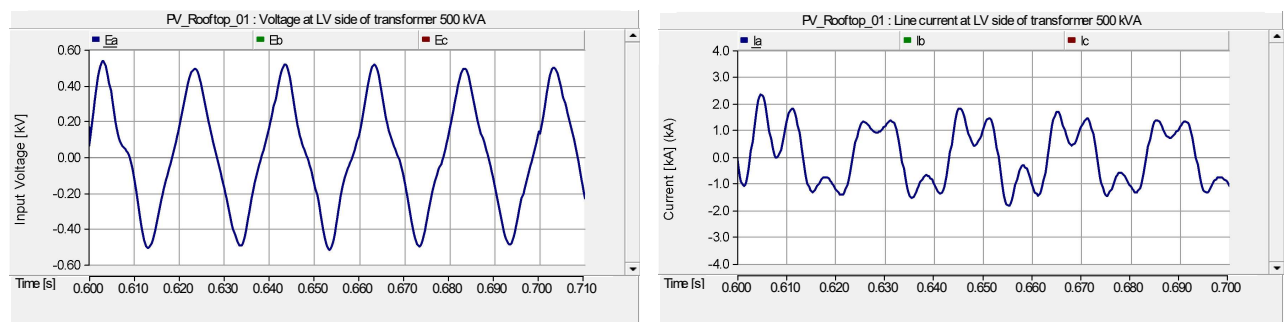

(a) Phase A
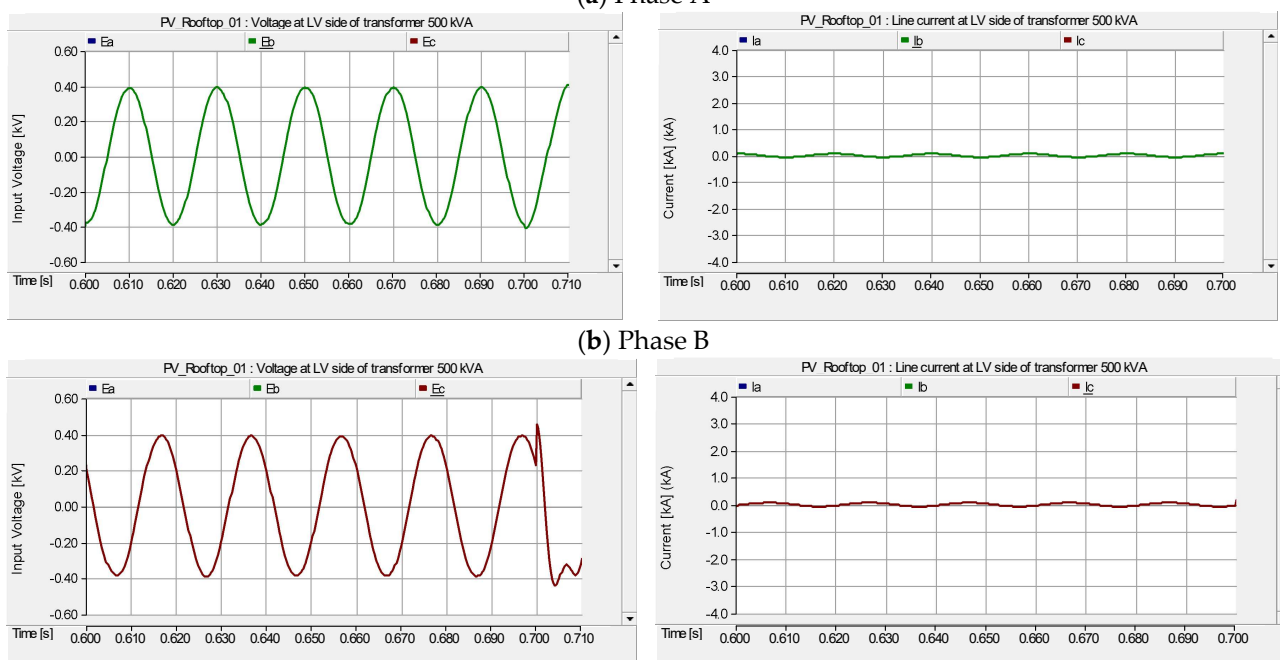

(b) Phase B

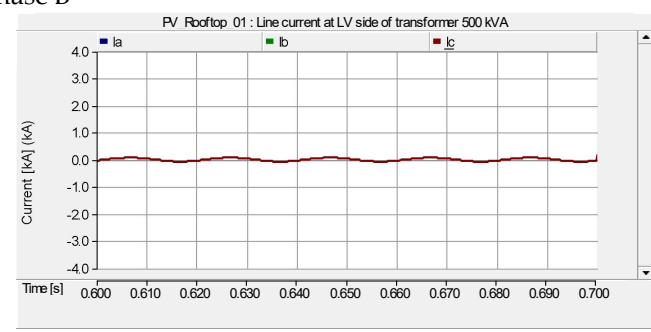

(c) Phase $\mathrm{C}$

Figure 23. The voltage and current at the LV side $(0.4 \mathrm{kV})$ transformer $500 \mathrm{kVA}$ when the BRKA close circuit is at $0.6 \mathrm{~s}$. 
The corresponding frequency spectrums of Figure 23 are obtained and shown in Figure 24.

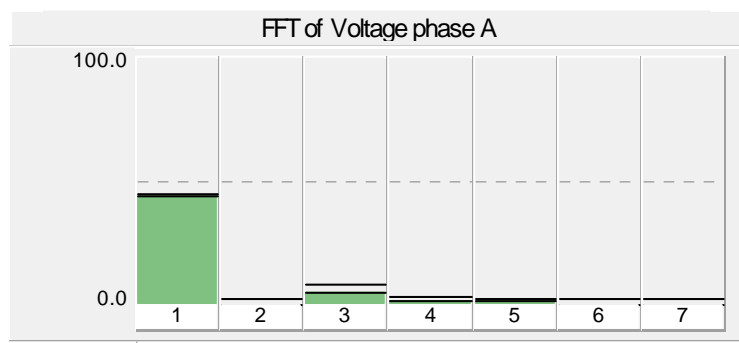

$\%$

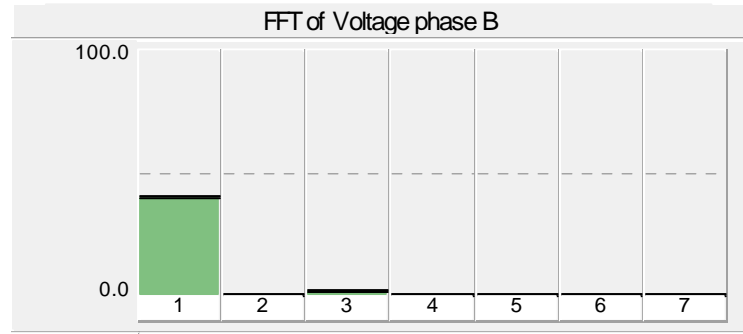

$\%$

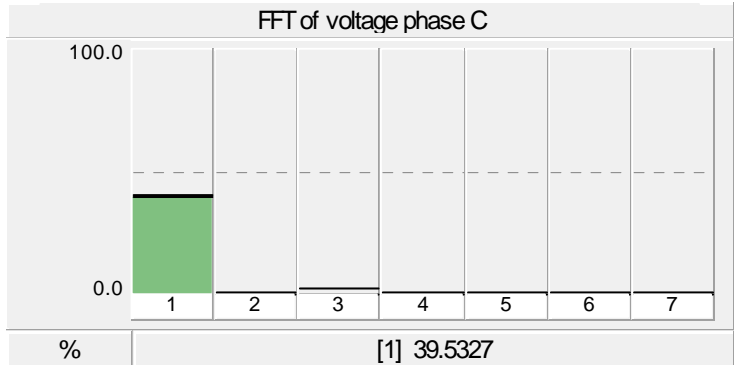

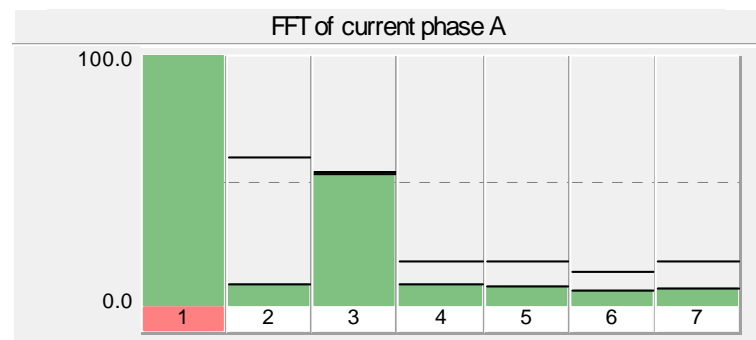

[1] 145.333

(a) Phase A

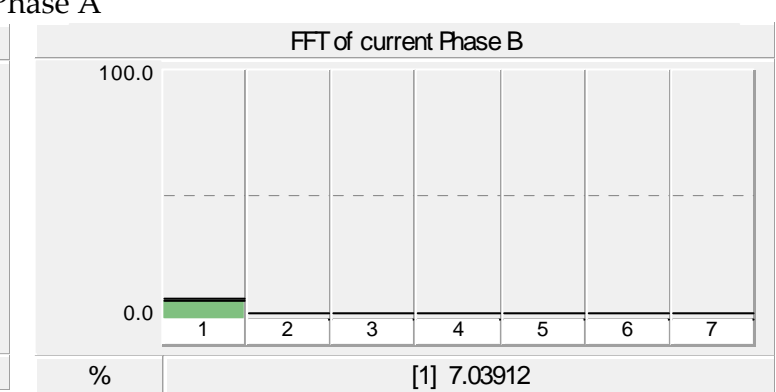

(b) Phase B

(c) Phase C

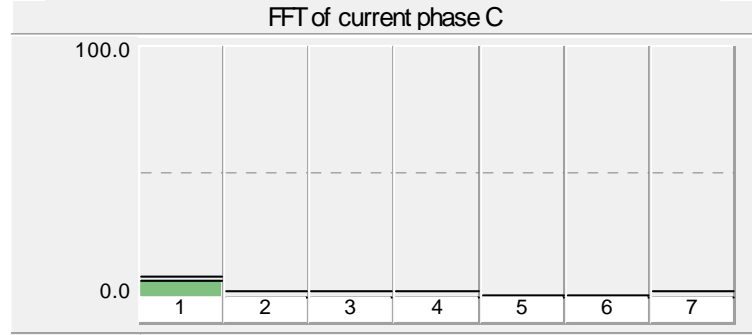

[1] 6.40018

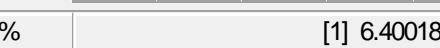

Figure 24. The frequency spectrum of the phase voltage and current at the LV side $(0.4 \mathrm{kV})$ transformer $500 \mathrm{kVA}$ when the BRKA close circuit is at $0.6 \mathrm{~s}$.

From the results in Figures 23 and 24, only phase A is affected by the ferroresonance. Its voltage consists of the fundamental mode ferroresonance while the current consists of the combination of the fundamental mode and quasi-periodic mode ferroresonances.

Second, the BRKC is closed at $0.7 \mathrm{~s}$. This connection yields the voltage and current as shown in Figure 25.
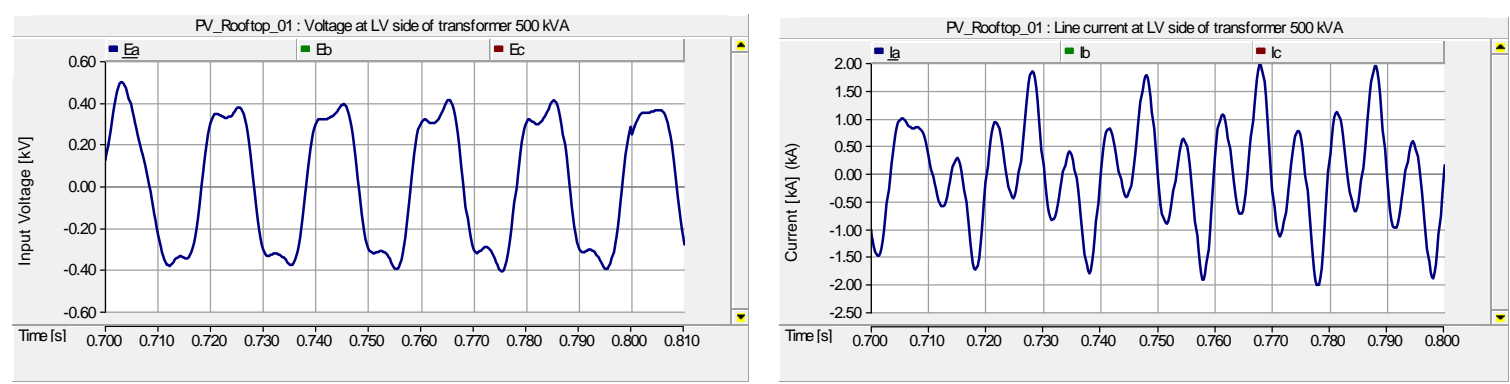

(a) Phase A

Figure 25. Cont. 

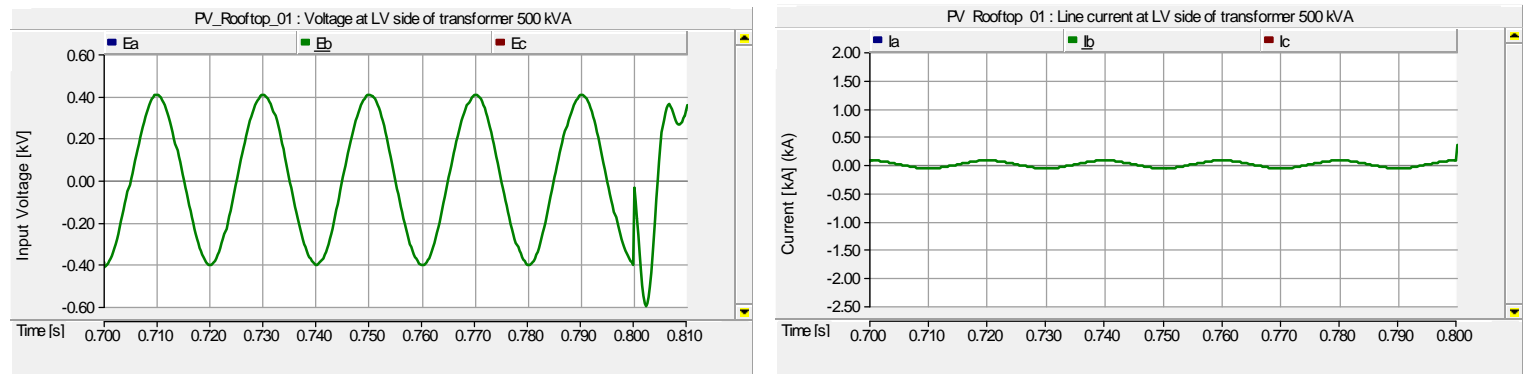

(b) Phase B
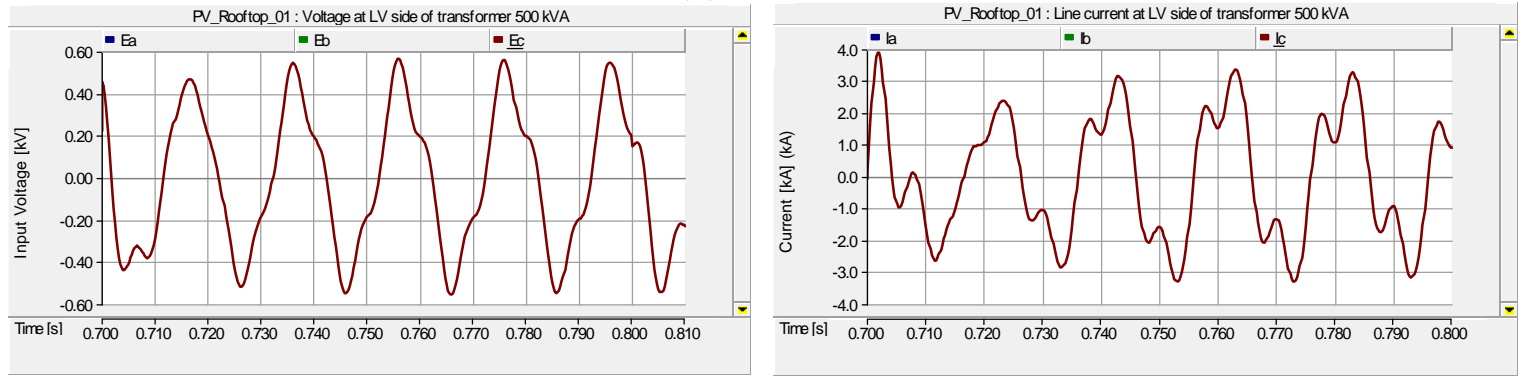

(c) Phase C

Figure 25. The voltage and current at the LV side $(0.4 \mathrm{kV})$ transformer $500 \mathrm{kVA}$ when the BRKC close circuit is at $0.7 \mathrm{~s}$.

The corresponding frequency spectrums of Figure 25 using FFT are shown in Figure 26.
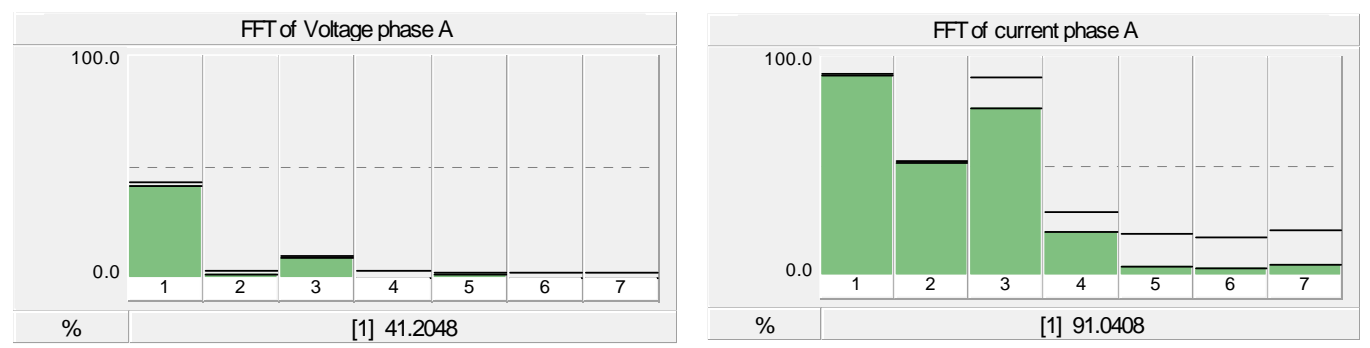

(a) Phase A
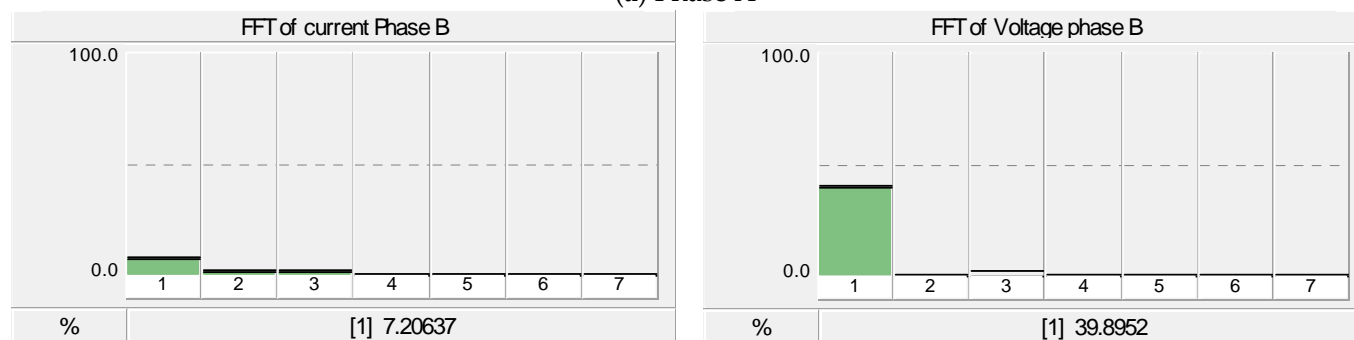

(b) Phase B
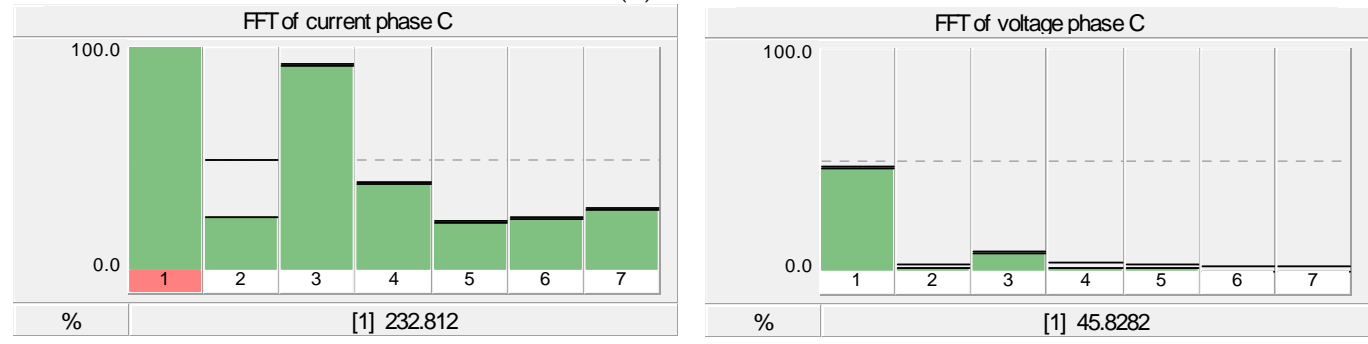

(c) Phase C

Figure 26. The frequency spectrums of the phase voltage and current at the LV side $(0.4 \mathrm{kV})$ transformer $500 \mathrm{kVA}$ when the BRKC close circuit is at $0.7 \mathrm{~s}$. 
From the results in Figures 25 and 26, phase A and phase $C$ are affected by ferroresonance. Their voltage consists of the fundamental mode ferroresonance while their current consists of a combination of the fundamental mode and quasi-periodic mode ferroresonances.

Finally, the BRKB is closed at $0.8 \mathrm{~s}$. This connection yields the voltage and current as shown in Figure 27.
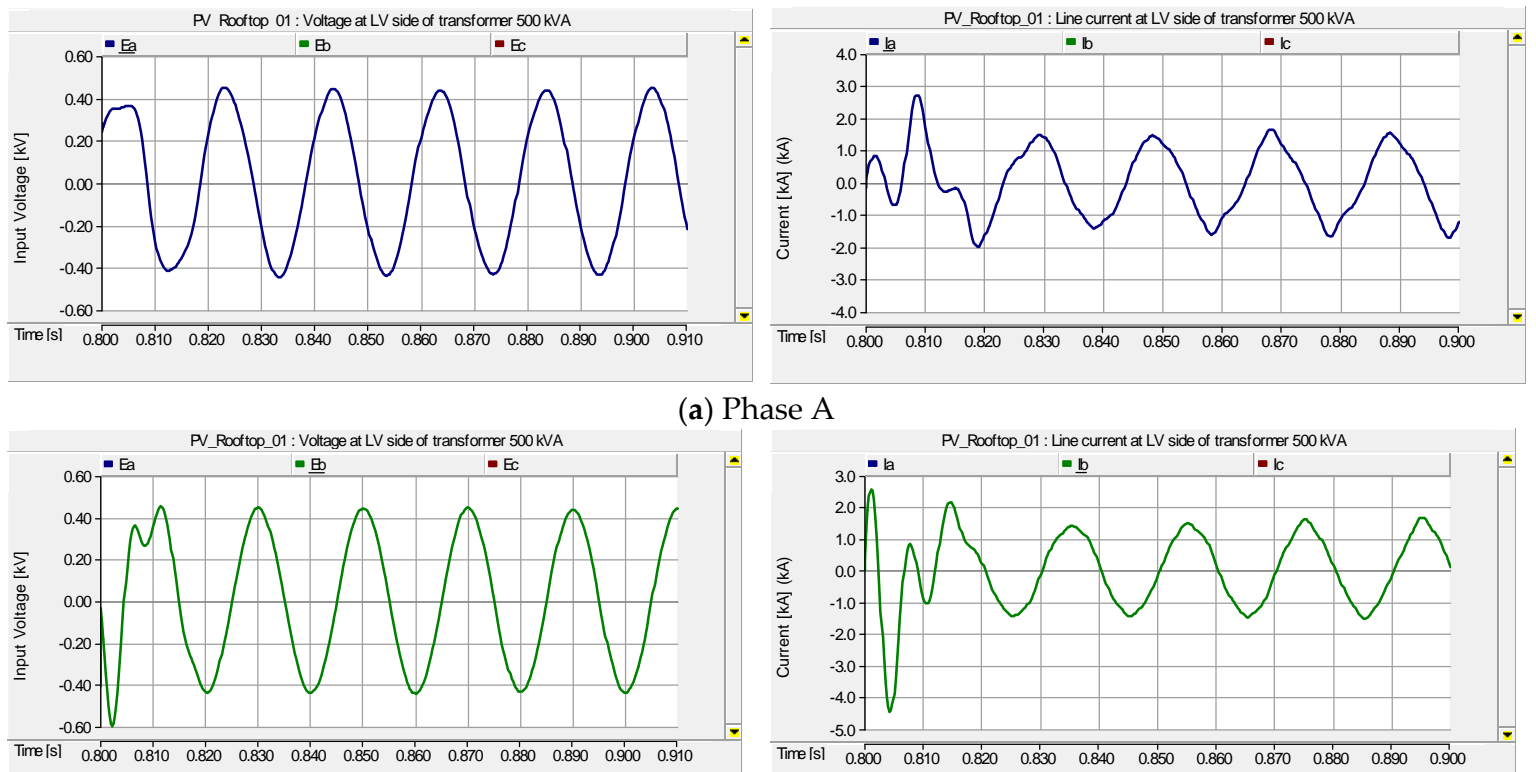

(a) Phase A
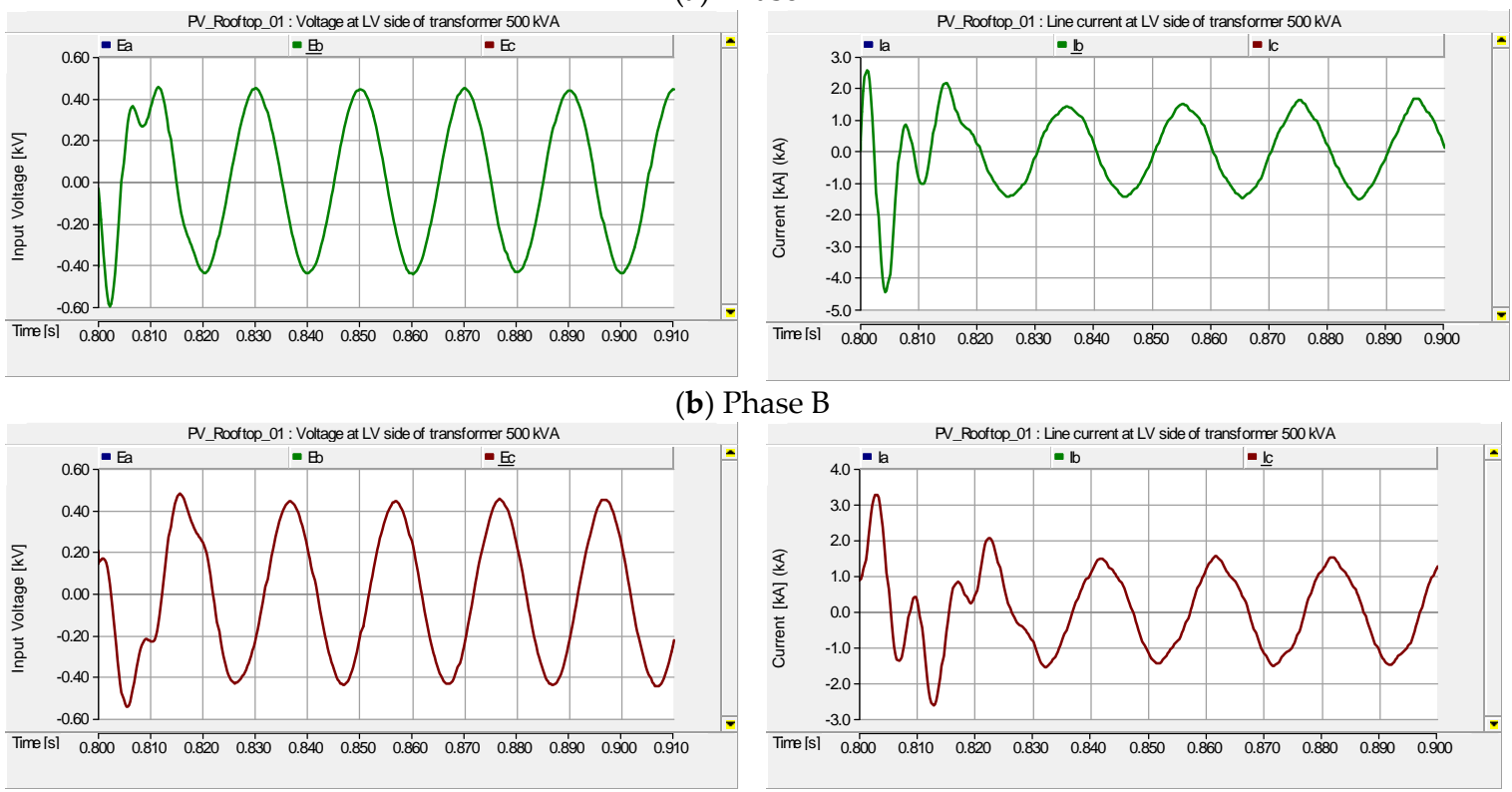

(c) Phase C

Figure 27. The voltage and current at the LV side $(0.4 \mathrm{kV})$ transformer $500 \mathrm{kVA}$ when the BRKB close circuit is at $0.8 \mathrm{~s}$.

The corresponding frequency spectrums of Figure 27 using FFT are shown in Figure 28.
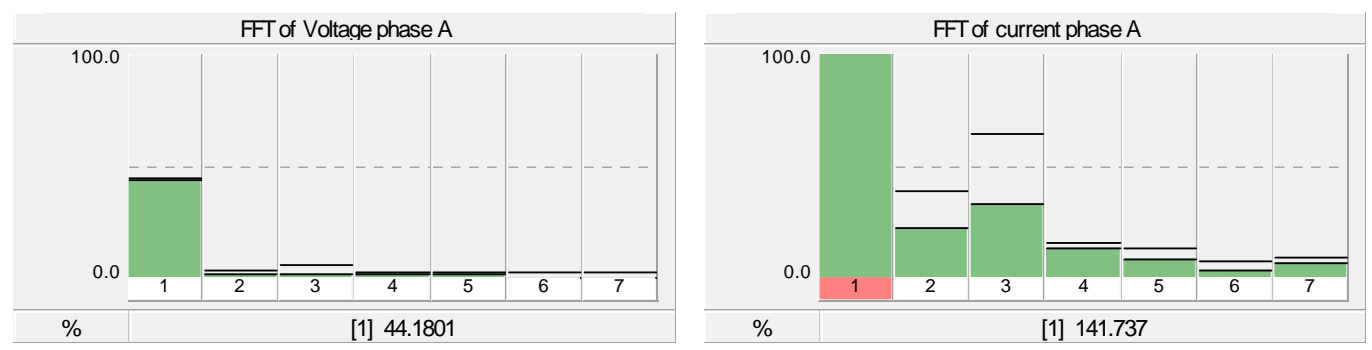

(a) Phase A

Figure 28. Cont. 

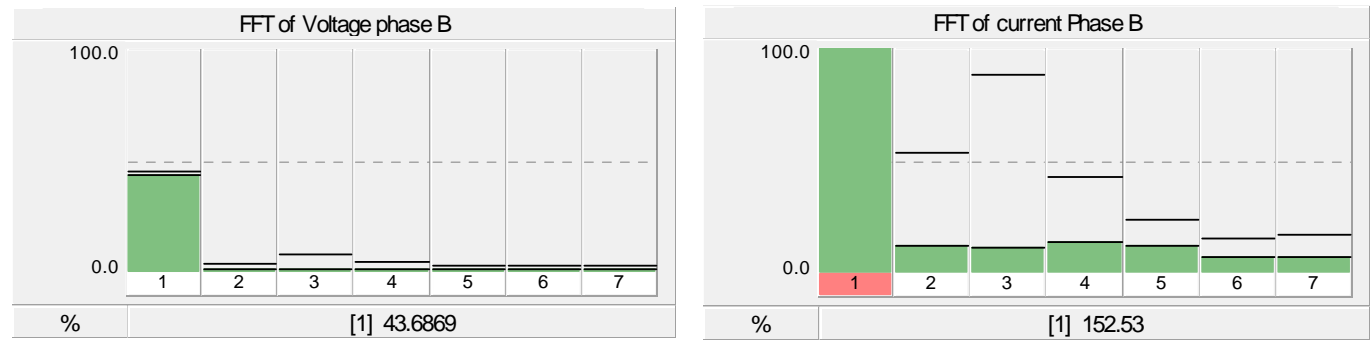

(b) Phase B
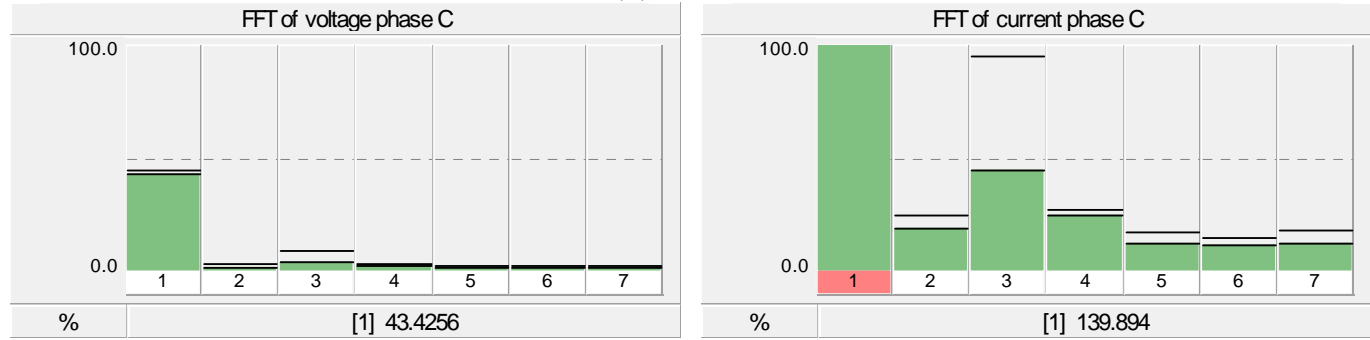

(c) Phase C

Figure 28. The frequency spectrums of the phase voltage and current at the LV side $(0.4 \mathrm{kV})$ transformer $500 \mathrm{kVA}$ when the BRKB close circuit is at $0.8 \mathrm{~s}$.

From the results in Figures 27 and 28, phases A, B and C are affected by the ferroresonance. Their voltage consists of the fundamental mode ferroresonance while their current consists of a combination of the fundamental mode and quasi-periodic mode ferroresonances. However, the effect of this phenomenon exists for a short time.

Furthermore, the ferroresonance that occurs in the system leads the voltage and current at the suburban home to have fluctuations as shown in Figure 29.
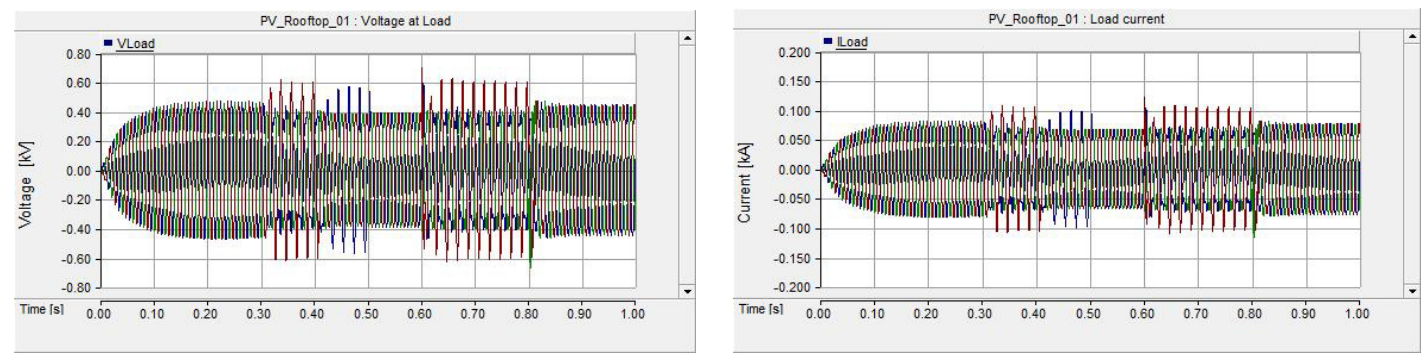

Figure 29. The voltage and current at the simulation load of a Suburban home.

For the HV side of the distribution transformer, its voltages are not affected by ferroresonance since it is connected to the grid. However, the currents fluctuate due to this phenomenon, as shown in Figure 30.
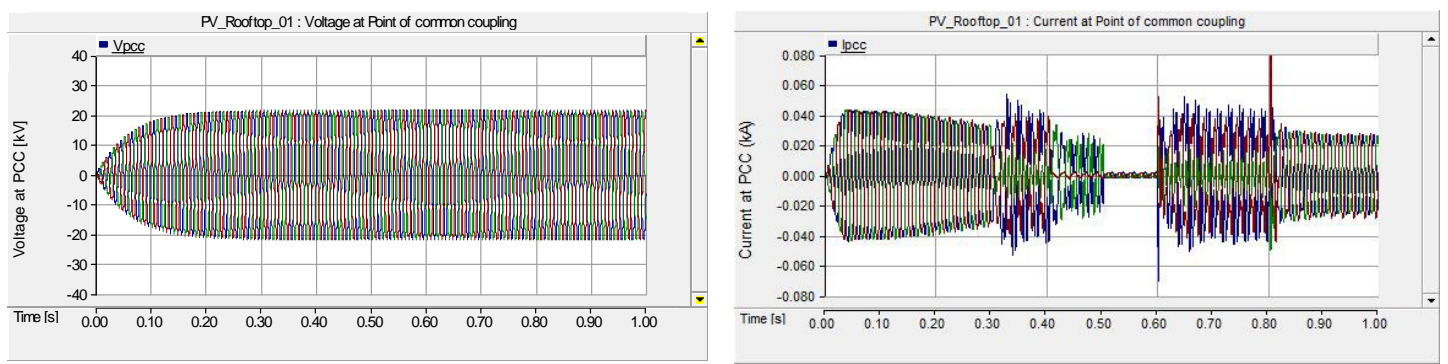

Figure 30. The voltage and current at the HV side of the distribution transformer. 
4.3. Case III: The Effect of Ferroresonance When Increasing the Capacity of PV Rooftop Systems from $1 \mathrm{~kW}$ to $500 \mathrm{~kW}$

In Case III, the effects of the PV system connection at the $500 \mathrm{kVA}$ transformer LV side with the step by step increasing of the installed capacity of the PV system are shown in Table 3.

Table 3. The simulation results of the increasing installation capacity of the PV system.

\begin{tabular}{|c|c|c|c|c|c|c|}
\hline $\begin{array}{l}\text { PV Install } \\
\text { Capacity } \\
\text { (kW) }\end{array}$ & $\begin{array}{l}\text { Vmax }(\mathrm{kV}, \mathrm{L}-\mathrm{L}) \text { at } \\
\text { Terminal Point of } \\
\text { Transformer }\end{array}$ & $\begin{array}{c}\text { Imax (kA) at } \\
\text { Terminal Point } \\
\text { of Transformer }\end{array}$ & $\begin{array}{l}\text { Vload Max. } \\
\text { (kV, L-L) }\end{array}$ & $\begin{array}{l}\text { Iload Max. } \\
\text { (kA) }\end{array}$ & $\begin{array}{l}\text { Max. HD } \\
\text { of Voltage } \\
(\%)\end{array}$ & $\begin{array}{c}\text { Ferroresonance } \\
\text { Phenomena }\end{array}$ \\
\hline 1 & 0.578 & 3.476 & 0.566 & 0.098 & 27.8 & Y \\
\hline 2 & 0.578 & 3.665 & 0.576 & 0.100 & 31.4 & Y \\
\hline 3 & 0.580 & 3.739 & 0.577 & 0.100 & 33.2 & Y \\
\hline 4 & 0.580 & 3.741 & 0.577 & 0.100 & 33.2 & Y \\
\hline 5 & 0.580 & 3.742 & 0.581 & 0.100 & 33.2 & Y \\
\hline 6 & 0.580 & 3.743 & 0.577 & 0.100 & 34.1 & Y \\
\hline 7 & 0.580 & 3.746 & 0.577 & 0.100 & 33.1 & $\mathrm{Y}$ \\
\hline 8 & 0.580 & 3.748 & 0.577 & 0.100 & 33.1 & Y \\
\hline 9 & 0.580 & 3.753 & 0.577 & 0.100 & 33.1 & Y \\
\hline 10 & 0.580 & 3.758 & 0.577 & 0.100 & 33.1 & Y \\
\hline 20 & 0.603 & 3.986 & 0.601 & 0.104 & 32.8 & Y \\
\hline 30 & 0.612 & 4.103 & 0.609 & 0.106 & 32.5 & $\mathrm{Y}$ \\
\hline 40 & 0.619 & 4.132 & 0.617 & 0.107 & 33.3 & Y \\
\hline 50 & 0.639 & 4.274 & 0.638 & 0.111 & 33.2 & Y \\
\hline 60 & 0.659 & 4.366 & 0.658 & 0.114 & 32.6 & Y \\
\hline 70 & 0.660 & 4.374 & 0.658 & 0.114 & 31.8 & $\mathrm{Y}$ \\
\hline 80 & 0.660 & 4.383 & 0.658 & 0.114 & 33.9 & $\mathrm{Y}$ \\
\hline 90 & 0.668 & 4.524 & 0.668 & 0.116 & 34.2 & $\mathrm{Y}$ \\
\hline 100 & 0.690 & 4.728 & 0.688 & 0.119 & 34.7 & Y \\
\hline 200 & 0.640 & 4.279 & 0.639 & 0.111 & 31.7 & Y \\
\hline 300 & 0.677 & 4.507 & 0.674 & 0.117 & 35.1 & Y \\
\hline 400 & 0.698 & 4.647 & 0.696 & 0.121 & 36.3 & Y \\
\hline 500 & 0.716 & 5.302 & 0.715 & 0.124 & 37.8 & $\mathrm{Y}$ \\
\hline
\end{tabular}

Because the installation of the PV systems grid connected in Thailand is preferred from a minimum of $1 \mathrm{~kW}$, Table 3 shows that a $1 \mathrm{~kW}$ PV system can lead to ferroresonance phenomena in the distribution transformer. In addition, the voltage and current values at the terminal transformer LV side are high. If the installed capacity of the PV system increases, the current in this area also increases and directly affects the distribution transformer.

From these results, the researcher found that the simulation results are different in some cases. The reasons for the differences are summarized as follows:

(1) The effect of the underground cable and distribution transformer configuration.

(2) The effect of magnetizing the core saturation from the distribution transformer used for the voltage divider.

(3) The effect of the supply voltage to a transformer primary winding that is connected to a ground or neutral separated wye or delta connection.

(4) The effect of the increase of the voltage source in the system which, in this case, is the PV rooftop system on the LV side.

The results reveal that the ferroresonance overvoltage and overcurrent phenomena can happen in this system under the saturation transformer with the capacitance of the $20 \mathrm{~km}$ underground cable, the capacitance of the $200 \mathrm{~m}$ transmission line PI section, the nonlinear characteristic of the 1 MVA and $500 \mathrm{kVA}$ transformer, and the PV system source. Moreover, the major principle of the ferroresonance phenomena is an unbalanced switching operation. If there are differences in switching cutouts disconnected and connected, they will cause damage to the power system. The ferroresonance overvoltage will be $30-150 \mathrm{kV}$ in the MV side, and the overvoltage will be $0.5-1 \mathrm{kV}$; the overcurrent will 
be 2-6 kA in the LV side. The effect of this situation is the generation of the destruction of the electrical equipment and protection system. For this reason, the phenomena will not happen when three-phase disconnected switching cutouts are operated at the same time. However, when three-phase switching cutouts are operated at the same time, resonance transience will happen and can produce harmonic distortion of the current in the distribution network as demonstrated in Figures 23-25.

To prevent ferroresonance occurring in a transformer accidentally energized in only one or two phases (see Figure 3), the practical solutions consist of the following:

1. Lowering the value of the capacitance between the circuit breaker and transformer below its critical value by using, for example, a circuit breaker cubicle closer to the transformer or placing circuit breakers just upstream of the transformers and closing them only when the voltage has been restored to all three-phases.

2. Avoiding use of the transformers delivering an active power which is lower by $10 \%$ than its rated apparent power.

3. Avoiding no-load energizing.

4. Prohibiting single-phase operations or fuse protection, blowing of which results in single-pole breaking.

5. Prohibiting live work on a cable-transformer assembly when the cable length exceeds a certain critical length.

6. Resistance-earthing of the neutral of the supply substation.

7. Solidly earthing the neutral (permanently or only during energizing and de-energizing operations) of a transformer whose primary is wye-connected (available neutral).

\section{Conclusions}

This paper presents the analysis of ferroresonance phenomena in $0.4 / 22 \mathrm{kV}$ distribution transformers with a PV system source using the software simulation approach. The results explain that ferroresonance overvoltage and overcurrent will occur when the system consists of a PV rooftop source, the capacitance in a long transmission line, a nonlinear distribution transformer with saturation characteristic and the usage of single-phase switching cutouts in the system. In addition, when the installed capacity of the PV system increases, the current at the terminal distribution transformer also increases and causes damage to the distribution transformer. Typically, for the three-phases switching cut-out and cut-in, ferroresonance will not occur. To prevent ferroresonance in a PV grid connected system, many solutions can be applied. The usage of the three-phase switching cutouts for connecting and disconnecting the system or the multi-pole breaking switchgear is one of the solutions. Installing the ferroresonance suppression circuit to the transformer also prevents the derogation. If the single-phase switching cutouts is installed, the proper sequent switching must be considered. In addition, the distribution transformer must be in the normal condition (without saturation characteristic). Moreover, a wide overview of this phenomenon that resulted from simulation studies can help the operator in electrical maintenance departments to get quick possible solutions to the problem. Therefore, it will allow the analysis of the risks and the evaluation of the solution to be completed efficiency.

Author Contributions: N.T. designed, performed and analyzed data from the simulations; B.P. and H.O. assisted for the data analysis and provided the suggestions for the writing.

Funding: Rajamangala University of Technology Thanyaburi, Thailand.

Conflicts of Interest: The authors declare no conflict of interest. 


\section{References}

1. Wareing, J.B.; Perrot, F. Ferroresonance Overvoltages in Distribution Networks. In Proceedings of the IEE Colloquium on Warning! Ferroresonance Can Damage Your Plant (Digest No: 1997/349), Glasgow, UK, 12 November 1997; pp. 5/1-5/7.

2. Walling, R.A. Ferroresonance in Low-Loss Distribution Transformers. In Proceedings of the 2003 IEEE Power Engineering Society General Meeting, Toronto, ON, Canada, 13-17 July 2003; Volume 2, p. 1222.

3. Dugan, R.C. Examples of ferroresonance in distribution. In Proceedings of the 2003 IEEE Power Engineering Society General Meeting, Toronto, ON, Canada, 13-17 July 2003; Volume 2, p. 1215.

4. Dolan, E.J.; Gillies, D.A.; Kimbark, E.W. Ferroresonance in a transformer switched with an EVH line. IEEE Trans. Power Appar. Syst. 1972, PAS-91, 1273-1280. [CrossRef]

5. Emin, Z.; Zahawi, B.A.T.A.; Auckland, D.W.; Tong, Y.K. Ferroresonance in Electromagnetic Voltage Transformers: A Study Based on Nonlinear Dynamics. IEE Proc. Gener. Transm. Distrib. 1997, 144, 383-387. [CrossRef]

6. Radmanesh, H.; Abassi, A.; Rostami, M. Analysis of Ferroresonance Phenomena in Power Transformers Including Neutral Resistance Effect. In Proceedings of the IEEE Southeastcon 2009, Atlanta, GA, USA, 5-8 March 2009.

7. Radmanesh, H.; Gharehpetian, G.B.; Fathi, H. Ferroresonance of Power Transformers Considering Non-linear Core Losses and Metal Oxide Surge Arrester Effects. Electr. Power Compon. Syst. 2012, 40, 463-479. [CrossRef]

8. Corea-Araujo, J.A.; Barrado-Rodrigo, J.A.; Gonzalez-Molina, F.; Guasch-Pesquer, L. Ferroresonance Analysis on Power Transformers Interconnected to Self-Excited Induction Generators. Electr. Power Compon. Syst. 2016, 44, 359-368. [CrossRef]

9. Iravani, M.R.; Chaudhary, A.K.S.; Giesbrecht, W.J.; Hassan, I.E.; Keri, A.J.F.; Lee, K.C.; Martinez, J.A.; Morched, A.S.; Mork, B.A.; Parniani, M.; et al. Modeling and analysis guidelines for slow transients. III. The study of ferroresonance. IEEE Trans. Power Deliv. 2000, 15, 255-265. [CrossRef]

10. Sakarung, P.; Chatratana, S. Application of PSCAD/EMTDC and Chaos Theory to Power System Ferroresonance Analysis. In Proceedings of the International Conference on Power Systems Transients (IPST'05), Montreal, QC, Canada, 19-23 June 2005. Paper No. IPST05-227.

11. Hernández, J.C.; de la Cruz, J.; Vidal, P.G.; Ogayar, B. Conflicts in the distribution network protection in the presence of large photovoltaic plants: The case of ENDESA. Int. Trans. Electr. Energy Syst. 2013, 23, 669-688. [CrossRef]

12. Batora, B.; Toman, P. Using of PSCAD software for simulation Ferroresonance Phenomenon in Power system with the three-phase power transformer. Trans. Electr. Eng. 2013, 2, 102-105.

13. Gonen, T. Electric Power Distribution System Engineering; MaGraw-Hill College Div.: New York, NY, USA, 1985; Volume I.

14. Buigues, G.; Zamora, I.; Valverde, V.; Mazón, Á. Ferroresonance in three-phase Power Distribution Transformer: Sources, Con sequences and Prevention. In Proceedings of the 19th International Conference on Electricity Distribution, Vienna, Austria, 21-24 May 2007.

15. Jacobson, D.A.N. Examples of Ferroresonance in a High Voltage Power System. In Proceedings of the 2003 IEEE Power Engineering Society General Meeting, Toronto, ON, Canada, 13-17 July 2003; pp. 1206-1212.

16. Daily Report. Available online: http:/ / thanyaratthaicenter.com/2017/03/30 / (accessed on 6 June 2017).

17. Chaianong, A.; Pharino, C. Outlook and challenges for promoting solar photovoltaic rooftops in Thailand. Renew. Sustain. Energy Rev. 2015, 48, 359-372. [CrossRef]

18. Energy Policy and Planning Office. IPP, SPP and VSPP Status; Energy Statistic; Energy Policy and Planning Office, Ministry of Energy: Bangkok, Thailand, 2012.

19. Thanomsat, N.; Plangklang, B. Ferroresonance phenomenon in PV system at LV side of three-phase power transformer using of PSCAD simulation. In Proceedings of the 13th International Conference on Electrical Engineering/Electronics, Computer, Telecommunications and Information Technology (ECTI-CON), Chiang Mai, Thailand, 28 June-1 July 2016.

20. Caamano, E.; Thornycroft, J.; de Moor, H.; Cobben, S.; Jantsch, M.; Erge, T.; Laukamp, H.; Suna, D.; Gaiddon, B. State of the Art on Dispersed PV Power Generation: Impact of PV Distributed Generation and Electricity Networks; Intelligent Energy Europe: Brussels, Belgium, 2007. 
21. Papaioannou, I.T.; Bouhouras, A.S.; Marinopoulos, A.G.; Alexiadis, M.C.; Demoulias, C.S.; Labridis, D.P. Harmonic impact of small photovoltaic systems connected to the LV distribution network. In Proceedings of the 2008 5th International Conference on the European Electricity Market, Lisboa, Portugal, 28-30 May 2008; pp. 1-6.

22. Busrah, A.M.; Ramachandaramurthy, V.K. The Impact of grid connected photovoltaic gereration system to voltage rise in low voltage network. In Proceedings of the 3rd International Conference on Development, Energy, Environment and Economic (DEEE'12), Paris, France, 2-4 December 2012.

23. Grady, W.M.; Santoso, S. Understanding power system harmonics. IEEE Power Eng. Rev. 2001, $21,8-11$. [CrossRef]

24. Schlabbach, J. Harmonic current emission of photovoltaic installations under system conditions. In Proceedings of the 2008 5th International Conference on the European Electricity Market, Lisboa, Portugal, 28-30 May 2008; pp. 1-5.

25. Batrinu, F.; Chicco, G.; Schlabbach, J.; Spertino, F. Impacts of grid-connected photovoltaic plant operation on the harmonic distortion. In Proceedings of the 2006 IEEE Mediterranean Electrotechnical Conference (MELECON), Malaga, Spain, 16-19 May 2006; pp. 861-864.

26. Menti, A.; Zacharias, T.; Milias-Argitis, J. Harmonic distortion assessment for a single-phase grid-connected photovoltaic system. Renew. Energy 2011, 36, 360-368. [CrossRef]

27. Chicco, G.; Schlabbach, J.; Spertino, F. Characterisation and assessment of the harmonic emission of grid-connected photovoltaic systems. In Proceedings of the 2005 IEEE Russia Power Tech, St. Petersburg, Russia, 27-30 June 2005; pp. 1-7.

28. McNeil, B.W.; Mirza, M.A. Estimated power quality for line commutated photovoltaic residential system. IEEE Trans. Power Appar. Syst. 1983, PAS-102, 3288-3295. [CrossRef]

29. Di Manno, M.; Varilone, P.; Verde, P.; de Santis, M.; di Perna, C.; Salemme, M. User friendly smart distributed measurement system for monitoring and assessing the electrical power quality. In Proceedings of the AEIT International Annual Conference (AEIT), Naples, Italy, 14-16 October 2015.

30. Ang, S.P. Erroresonance Simulation Studies of Transmission Systems. Ph.D. Thesis, The University of Manchester, Manchester, UK, 2010.

31. Marti, J.R.; Soudack, A.C. Ferroresonance in power systems: Fundamental solutions. IEE Proc. C Gener. Transm. Distrib. 1991, 138, 321-329. [CrossRef]

32. Jacobson, D.A.N. Field Testing, Modelling and Analysis of Ferroresonance in a High Voltage Power System. Ph.D. Thesis, The University of Manitoba, Winnipeg, MB, Canada, August 2000.

33. Valverde, V.; Mazón, A.J.; Zamora, I.; Buigues, G. Ferroresonance in Voltage Transformers: Analysis and Simulations. Renew. Energy Power Qual. J. 2007, 1, 465-471. [CrossRef] 